\title{
How do air ions reflect variations in ionising radiation in the lower atmosphere in a boreal forest?
}

\author{
Xuemeng Chen ${ }^{1}$, Veli-Matti Kerminen ${ }^{1}$, Jussi Paatero ${ }^{2}$, Pauli Paasonen ${ }^{1}$, Hanna E. Manninen ${ }^{1}$, Tuomo Nieminen ${ }^{1,3}$, \\ Tuukka Petäjä ${ }^{1}$, and Markku Kulmala ${ }^{1}$ \\ ${ }^{1}$ Department of Physics, University of Helsinki, P.O. Box 64, 00014 Helsinki, Finland \\ ${ }^{2}$ Finnish Meteorological Institute, Observation services, P.O. Box 503, 00101 Helsinki, Finland \\ ${ }^{3}$ Department of Applied Physics, University of Eastern Finland, P.O. Box 1627, 70211 Kuopio, Finland
}

Correspondence to: Xuemeng Chen (xuemeng.chen@helsinki.fi)

Received: 23 May 2016 - Published in Atmos. Chem. Phys. Discuss.: 20 June 2016

Revised: 30 September 2016 - Accepted: 21 October 2016 - Published: 16 November 2016

\begin{abstract}
Most of the ion production in the atmosphere is attributed to ionising radiation. In the lower atmosphere, ionising radiation consists mainly of the decay emissions of radon and its progeny, gamma radiation of the terrestrial origin as well as photons and elementary particles of cosmic radiation. These types of radiation produce ion pairs via the ionisation of nitrogen and oxygen as well as trace species in the atmosphere, the rate of which is defined as the ionising capacity. Larger air ions are produced out of the initial charge carriers by processes such as clustering or attachment to preexisting aerosol particles. This study aimed (1) to identify the key factors responsible for the variability in ionising radiation and in the observed air ion concentrations, (2) to reveal the linkage between them and (3) to provide an in-depth analysis into the effects of ionising radiation on air ion formation, based on measurement data collected during 20032006 from a boreal forest site in southern Finland. In general, gamma radiation dominated the ion production in the lower atmosphere. Variations in the ionising capacity came from mixing layer dynamics, soil type and moisture content, meteorological conditions, long-distance transportation, snow cover attenuation and precipitation. Slightly similar diurnal patterns to variations in the ionising capacity were observed in air ion concentrations of the cluster size $(0.8-1.7 \mathrm{~nm}$ in mobility diameters). However, features observed in the $0.8-$ $1 \mathrm{~nm}$ ion concentration were in good connection to variations of the ionising capacity. Further, by carefully constraining perturbing variables, a strong dependency of the cluster ion concentration on the ionising capacity was identified, proving the functionality of ionising radiation in air ion produc-
\end{abstract}

tion in the lower atmosphere. This relationship, however, was only clearly observed on new particle formation (NPF) days, possibly indicating that charges after being born underwent different processes on NPF days and non-event days and also that the transformation of newly formed charges to cluster ions occurred in a shorter timescale on NPF days than on non-event days.

\section{Introduction}

Ambient radioactivity in the lower atmosphere supplies ionising energy for the production of electric charges in the air. It consists of natural and anthropogenic radioactivity. The anthropogenic fraction comes mainly from routine and accidental emissions from nuclear power plants and related facilities as well as nuclear detonations. Minor emissions of natural radioactivity occur also in connection with various mining activities. Natural radioactivity is composed of the decay emissions of naturally occurring radionuclides and cosmic radiation. Alpha and beta particles as well as the associated gamma and X-ray photons constitute the ionising radiation from natural radionuclides. ${ }^{222} \mathrm{Rn}$ is a naturally occurring radioactive gas that is the daughter nuclide of ${ }^{226} \mathrm{Ra}$, which is typically present in soil grains. Naturally two other isotopic forms of radon exist as well, ${ }^{219} \mathrm{Rn}$ and ${ }^{220} \mathrm{Rn}$, but in trace quantities. Once formed, radon can diffuse through soil pores and eventually enter into the atmosphere (Chen et al., 2016; Nazaroff, 1992). Radon and its progeny undergo alpha and beta decay in the atmosphere and, together with the accom- 
panying gamma radiation, supply the energy for ionisation. Apart from radon, gamma radiation from the Earth's crust as well as photons and elementary particles of cosmic radiation also contribute to the creation of electric charges in the lower atmosphere. In the case of cosmic radiation near the ground, most of the ionisation of air is due to muons, with minor contributions from neutrons, photons and electrons (Goldhagen, 2000). Typically, $32.5-35 \mathrm{eV}$ is needed to produce an ion pair in the atmosphere (Krause et al., 2002), with an average expenditure of $34 \mathrm{eV}$ per ion pair often accepted in the lower atmosphere (Jesse and Sadaukis, 1957; Laakso et al., 2004; Wilkening, 1981).

Due to the atmospheric abundance of nitrogen $\left(\mathrm{N}_{2}\right)$ and oxygen $\left(\mathrm{O}_{2}\right)$, their derivatives are the initial carriers of electric charges generated from the ionisation process. These initial charge carriers are known as primary ions, which can be an electron or simple atomic or molecular ions. Primary ions are consumed either directly or via the formation of more complex molecular ions by (1) ion-ion recombination, (2) clustering, (3) charge transfer to pre-existing aerosol particles (or clusters) or gaseous species in the atmosphere and (4) sink to foreign surfaces. These processes may involve both chemical reactions and physical transformations. The recombination and sink to foreign surfaces lead to a reduced amount of electric charges in the air, whereas the clustering and charge transfer result in either charged or neutral gaseous species, clusters and aerosol particles. The term "air ion" refers to all airborne substances that are electrically charged, ranging from primary ions to charged aerosol particles. The relationship between primary ions, molecular ions and cluster ions is illustrated in Fig. 1.

Air ions were historically concerned in the discipline of atmospheric electricity (Israël, 1970), because their flow in the electric field of the Earth-atmosphere system serves as the measurable conduction current in the atmosphere (Harrison and Carslaw, 2003; Tinsley, 2008; Wilson, 1921). The interest in atmospheric electricity could be traced back to the early 18th century, when thunderstorms were suggested to be electrical phenomena (Herbert, 1997). However, only after Benjamin Franklin proposed the idea to draw electricity down from lightning in 1752 was this theory confirmed, and the study of atmospheric electricity became popular (Herbert, 1997; Tinsley, 2008). Early efforts in this field were substantially invested in understanding lightning and electrification of clouds (e.g. Canton, 1753a, b; Franklin, 1751), even though there were reports on observations of atmospheric electricity under fair weather conditions (Bennett and Harrison, 2007; Canton, 1753b; Read, 1792). Why the air was conductive could not, however, be explained. Meanwhile, Charles-Augustin de Coulomb observed gradual discharge of a well-insulated electroscope around 1785 and he attributed his observation to the contact of suspending particles present in the air (De Angelis, 2014; Walter, 2012). This phenomenon was reproduced by Michael Faraday half a century later in 1835 (De Angelis, 2014). Thanks to the further improvement of the electroscope by William Thomson and Lord Kelvin (De Angelis, 2014; Flagan, 1998), Crookes (1878) found that the discharge rate of an electroscope decreases with a decreasing air pressure, suggesting that it is the air inside the instrument that manipulates the discharge. However, the reasoning remained undisclosed until the discovery of radioactivity by Wilhelm Röntgen, Henri Becquerel and Marie and Pierre Curie enabled Julius Elster and Hans Geitel from Germany and Charles Thomson Rees Wilson from Scotland to relate the spontaneous discharge of the electroscope to ionisation of the air by radioactive sources (Carlson and De Angelis, 2011; De Angelis, 2014; Wilson, 1895, 1899). Therefrom, the importance of air ions in the atmosphere emerged. Contemporaneously, the interest of Joseph John Thomson, director of the Cavendish Laboratory, in the charge carriers produced by ionising radiation motivated the development of instrumentations for measuring electrical charges in gases, leading to various valuable outcomes, e.g. the cloud chamber designed by C. T. R. Wilson, as well as techniques for measuring ion mobility by Ernest Rutherford and John Zeleny and for studying gaseous ion diffusion by John Sealy Townsend (Flagan, 1998; Robotti, 2006). These works laid the theoreti$\mathrm{cal}$ and instrumental foundation for later aerosol studies. The experimental results from C. T. R. Wilson's cloud chamber measurements in 1895 and 1899 on the influence of ionising radiation on the formation of cloud droplets brought interest in air ions to the atmospheric aerosol community. Inspired by these early works, advancements in atmospheric aerosol studies progressed both instrumentally and theoretically over the century (e.g. Aplin and Harrison, 2000; Hewitt, 1957; Hinds, 1999; Hogg, 1939; Mason and McDaniel, 1988; Millikan, 1923; Nolan, 1924; Reischl, 1991; RosellLlompart and Fernández de la Mora, 1993; Tammet, 1970, 1995, 2006).

Devices employed for ion studies comprise different types of aspiration condensers, ion mobility spectrometers (IMSs) and mass spectrometers (Cumeras et al., 2015; Hirsikko et al., 2011; Laskin et al., 2012; Tammet, 1970). Notably, modern key instruments for field observations of air ions are mainly aspiration contender-based devices and mass spectrometers, such as the Gerdien counter - an integral aspiration condenser (Aplin and Harrison, 2000; Gerdien, 1905; Vojtek et al., 2006) - ion spectrometers designed by Airel Ltd. - single or multiple channel aspiration condensers (Kulmala et al., 2016; Manninen et al., 2009; Mirme et al., 2007; Tammet, 2006, 2011) - and the atmospheric pressure interface time-of-flight mass spectrometer (APi-ToF) (Junninen et al., 2010). While aspiration condensers provide information on the concentration and mobility of charge carriers, mass spectrometers reveal mainly the chemical properties of them. The IMS, however, has a limited application in studying ambient ions due to difficulties in spectrum interpretation (Hirsikko et al., 2011). The purpose of these instrumentations is not only air ion or air conductivity observations but also 


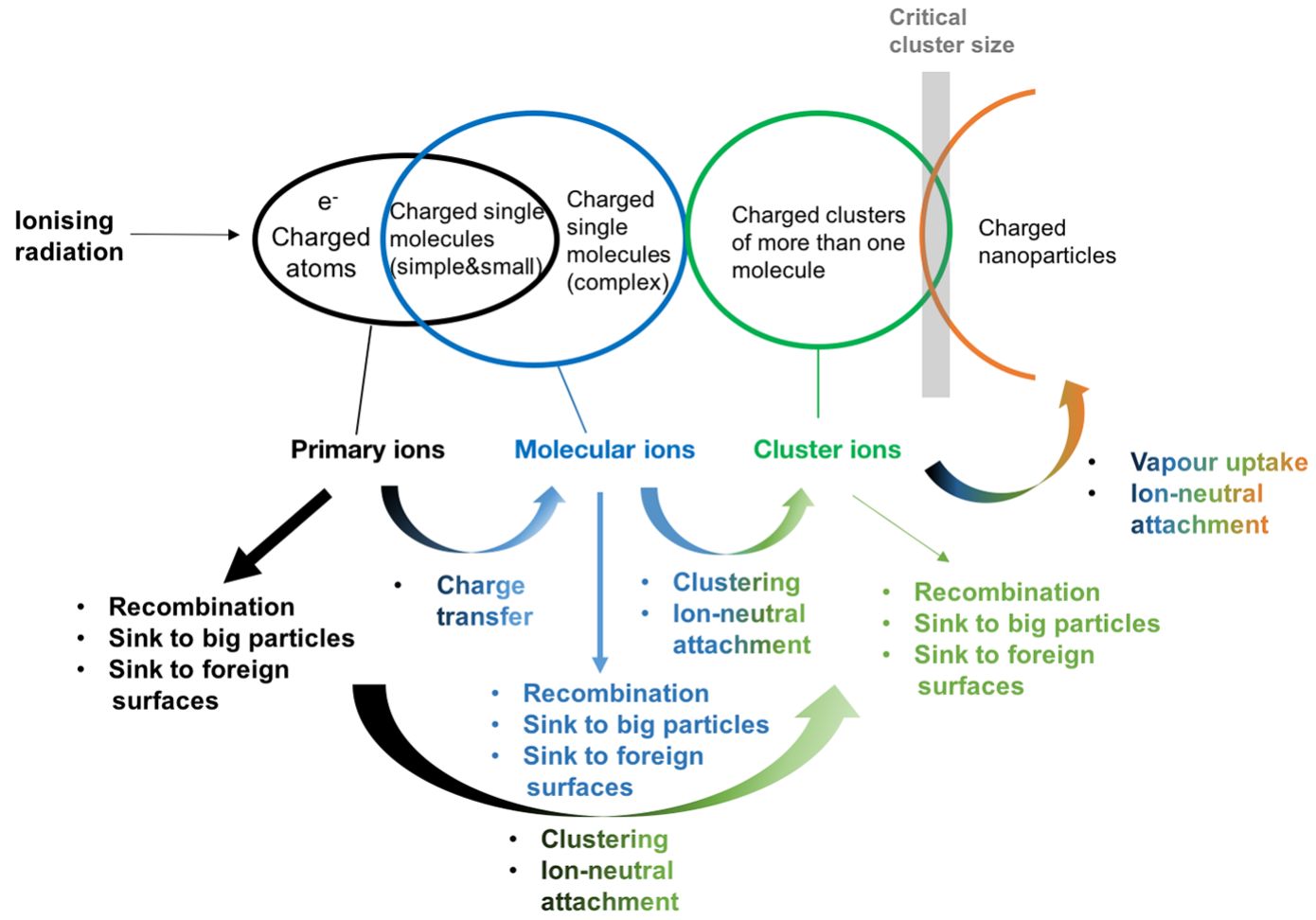

Figure 1. A schematic demonstration of the relationship between primary ions, molecular ions and cluster ions, as well as processes governing their formation and loss.

nano-material synthesis (Kruis et al., 1998) and the improvement of the fundamental understanding on the relationship between mobility, mass and size (Ku and Fernández de la Mora, 2009).

At present, the number size distribution of air ions can be measured down to about $0.8 \mathrm{~nm}$ in Millikan mobility size by using ion spectrometers (Manninen et al., 2009; Tammet, 2006, 2011). Most air ions concentrate at the lowest size band with a diameter of $0.8-1.7 \mathrm{~nm}$ (Manninen et al., 2009), which is generally known as the cluster size range (Tammet, 1995, 2012). In principle, this size range contains large molecular ions and clusters of molecular ions. Ions smaller than $0.8 \mathrm{~nm}$ comprise mostly relatively simple molecular ions, which are either primary ions or originate from the survived fraction of primary ions from recombination. The critical cluster size was found to be $1.5 \pm 0.3 \mathrm{~nm}$ for atmospheric nucleation (Kulmala et al., 2013). Once the critical cluster size is reached, further growth of a cluster in size is energetically favoured (Vehkamäki, 2006). Air ions that have sizes larger than the critical cluster size are therefore typically viewed as nanoparticles, observable especially during new particle formation (NPF) events (Kulmala et al., 2012; Manninen et al., 2009). However, since the atmosphere is a vast pool full of clusters with different structures and compositions, the critical cluster size is rather a size range than a single size, as demonstrated in Fig. 1. As a consequence, a clear size separation exists neither between cluster ions and charged nanopar- ticles nor between molecular ions and cluster ions. Thus, although the size range of $0.8-1.7 \mathrm{~nm}$ may contain molecular ions, cluster ions and even charged nanoparticles, we hereafter refer ions in this size range as cluster ions, unless otherwise mentioned.

Although it is known that ionising radiation creates ion pairs via ionisation in the atmosphere (Flagan, 1998; Harrison and Carslaw, 2003; Israël, 1970), except for a few attempts (Hirsikko et al., 2007; Laakso et al., 2004), only minor efforts have been invested in understanding the connection between ionising radiation and observed air ions in the lower atmosphere. Moreover, there is a lack of quantification on the underlying processes. Such deficiencies prompt the motivation of this work to examine how variations in ionising radiation are reflected in observed air ions based on ambient measurement. The aims of this study are (1) to identify the key factors responsible for the variability in ionising radiation and in observed air ion concentrations, (2) to reveal the linkage of observed air ions to the variations in ionising radiation and (3) to provide an in-depth analysis on the effects of ionising radiation on air ion formation. We will first introduce factors that cause the seasonal and diurnal variability in ionising radiation and air ions and then exposit the connection of observed air ions to variations in ionising radiation and the influence of different atmospheric conditions on this relationship. To assist our analysis, we will determine theoretically the potential maximum production rate of ion pairs 
by ionising radiation, based on our ionising radiation measurements and an assumed average energy expenditure of $34 \mathrm{eV}$ for creating an ion pair, which is termed as the ionising capacity. The ionising capacity can be viewed as a measure of the theoretical maximum ionisation rate, which, however, may not well capture the true ionisation rate due to uncertainties in ionising radiation measurements, possible energy dissipation of ionising radiation in excitation and the invalidity concern associated with the use of $34 \mathrm{eV}$ per production of an ion pair at near ground level in our calculation.

\section{Materials and methods}

The data presented in this work were collected from a boreal forest site, which is known as the SMEAR II station located at Hyytiälä, Southern Finland $\left(61^{\circ} 51^{\prime} \mathrm{N}, 24^{\circ} 17^{\prime} \mathrm{E}\right.$; $181 \mathrm{~m}$ above sea level) (Hari and Kulmala, 2005), during 2003-2006. Monitoring devices for ionising radiation have been deployed to this site since 2000 and the air ion measurement was initialised in 2003. Both of these measurements have been integrated into the long-term monitoring system on the site. Other data used in this work included the condensation sink (CS; Kulmala et al., 2012) derived from the number size distribution of ambient aerosol particles, ambient relative humidity $(\mathrm{RH})$, soil water content (SWC), soil temperature, snow cover depth and modelled mixing layer height (MLH). The estimates of MLH were retrieved from the European Centre for Medium-Range Weather Forecasts (ECMWF) Meteorological Archival and Retrieval System (MARS), Reading, UK (www.ecmwf.int).

\subsection{Instrumentation and data processing}

The ionising radiation measurement system consists of a radon monitor and a gamma spectrometer. Both devices are maintained by the Finnish Meteorological Institute (FMI). The air ion data were obtained by a Balanced Scanning Mobility Analyser (BSMA) (Tammet, 2006), which is part of the aerosol monitoring system at the station. A differential mobility particle sizer (DMPS) has been responsible for observing the ambient aerosol number size distribution on this site since 1996. For the study period of 2003-2006, the data availability for air ions, particles, radon and gamma was 91 , 99,71 and $76 \%$, respectively, allowing the coverage of every single day-of-year by each parameter. Data are presented in local winter time (UTC+02:00).

\subsubsection{Ionising radiation measurement}

The radon monitor is a dual fixed filter-based instrument and measures the aerosol beta activity. Its inlet is fixed at $6 \mathrm{~m}$ above the ground and this device has been described in detail by Paatero et al. (1994). Briefly, it is made up of two cylindrical Geiger-Müller counters covered with glass-fibre filters in lead shielding. A pump controller directs the air- flow to each counter alternatively for a $4 \mathrm{~h}$ period, allowing the beta activity on the other counter to decay. The counting efficiency for beta particles is determined by the geometric configuration of the counting system together with the intrinsic detection efficiency of the GM tubes, which is 0.96 and $4.3 \%$ for ${ }^{214} \mathrm{~Pb}$ and ${ }^{214} \mathrm{Bi}$ beta particles, respectively. The cumulative counts are logged at $10 \mathrm{~min}$ intervals. The re-establishment of the radon activity concentration into $\mathrm{Bq} \mathrm{m}^{-3}$ from the recorded count rates was achieved following the method and assumption given by Paatero et al. (1994) and Chen et al. (2016).

The gamma spectrometer is a scintillation-type detector using a piece of $76 \mathrm{~mm} \times 76 \mathrm{~mm} \mathrm{NaI}(\mathrm{Tl})$ crystal as the detection medium (Hirsikko et al., 2007; Laakso et al., 2004). It is kept at the height of $1.5 \mathrm{~m}$ above the ground in a temperaturecontrolled shelter. Pulse height spectra over the energy range of $100-3000 \mathrm{keV}$ are recorded with a multichannel analyser and the total count rate within this energy range are registered with a time resolution of $10 \mathrm{~min}$. The total gain of the detecting system is kept constant via digital spectrum stabilisation using the ${ }^{40} \mathrm{~K}$ gamma peak $(1460 \mathrm{keV})$ as the reference. For the determination of the ionising capacity in this work, the total count rate data were used instead of the spectral information. The recorded total count rates were converted into dose rates in the air $\left(\mu \mathrm{Sv} \mathrm{h}^{-1}\right)$ by a calibration factor obtained from an instrumental comparison to a pressurised ionisation chamber. Thus, the obtained dose rates take into account ionisation by both gamma radiation of terrestrial origins and from radon decays and cosmic ray constituents. However, a portion of high-energy cosmic ray muons may not be well detected by our counting system, possibly due to their weak interaction with the detector material or their light production leading to electrical pulses exceeding the dynamic range of the instrumentation.

\subsubsection{Air ion measurement}

The most state-of-the-art measurement techniques nowadays, usually employing a mass spectrometer as the detector, such as the APi-ToF (Junninen et al., 2010, 2016), are able to track air ions down to molecular sizes and characterise their chemical composition, but they lack the capability for providing information on the number concentration. Ion spectrometers are the most deployed type of devices for the study of air ion concentrations in segregated mobility channels (Hirsikko et al., 2011). The BSMA (Tammet, 2006) and the Neutral Cluster and Air Ion Spectrometer (NAIS) (Kulmala et al., 2007; Manninen et al., 2016; Mirme and Mirme, 2013) are examples in this category. The highest measurable mobility with these ion spectrometers is $3.2 \mathrm{~cm}^{2} \mathrm{Vs}^{-1}$ (Mirme and Mirme, 2013; Tammet, 2006, 2011), equivalent to a mobility diameter of about $0.8 \mathrm{~nm}$ based on the StokesMillikan equation. The mobility size of a particle may vary with the choice of a mobility diameter model as well as parameters and coefficients used therein (e.g. Ehn et al., 2011; 
Tammet, 1995, 2011; Mäkelä et al., 1996; Fernandez-Garcia and Fernandez de la Mora, 2013) .

Ambient air ion data used in this work were measured by a BSMA. The inlet of this instrument was at a height of $1.5 \mathrm{~m}$ above the ground. The BSMA is an integral-type counter (Tammet, 1970), which offers air ion mobility spectra by a continuous voltage-scanning system. It is composed of two plain aspiration condensers, one for each polarity. An electrofilter is installed at the inlet of each condenser. The BSMA has a total flow rate of $2640 \mathrm{~L} \mathrm{~min}^{-1}$, which is split into two streams at the inlet, supplying each condenser with a flow of $1320 \mathrm{~L} \mathrm{~min}^{-1}$. For either condenser, only one-eighth of the air stream passing through the electrofilter contains air ions, which is taken as the sample flow, leaving the rest ionfree fraction as the sheath flow. After the electrofilter, there exists an electric field in each condenser, created between a grounded collecting electrode and a repelling electrode that is kept at a high potential, where the trajectories of sampled air ions are deflected towards the collecting electrode. A $33 \mathrm{~mm}$ long and $170 \mathrm{~mm}$ wide sensing unit is inlaid on the counter electrode of each polarity. Both sensing units share a common electrometer for counting the captured ions. A bridging circuit balances the voltage supply onto the repelling electrodes, so that the induced electric currents on the collectors during the voltage scanning are equal in magnitudes, but of opposite polarity. This design avoids the generation of noise in the common electrometer. The BSMA segregates air ions based on their mobility into 16 channels in the range of $0.032-3.2 \mathrm{~cm}^{2} \mathrm{Vs}^{-1}$. A full measurement cycle scanning through the mobility range for both polarities takes $10 \mathrm{~min}$. The air ion number concentration measured in the mobility domain was automatically processed into number size distributions by the recording programme, with the particle size expressed in Tammet's mass diameter (Tammet, 1995, 2006), which was subsequently converted to the mobility diameter based on the mobility size conversion model proposed by Tammet (1995) and the Stokes-Millikan equation. The core of the Tammet model lies on a modified Millikan equation, which approaches the Chapman-Enskog equation in the free molecular scale and the Millikan equation in the macroscopic scale. The equivalent mobility diameter range of the BSMA is $0.8-8 \mathrm{~nm}$. In this work, particle sizes are always presented in mobility diameters.

\subsubsection{Other instrumentation}

A DMPS gives the information on the aerosol number size distribution (Wiedensohler et al., 2012). At the SMEAR II station, a twin-DMPS system is deployed, with one responsible for the mobility size range of 3-50 nm and the other for larger sizes (Aalto et al., 2001; Kulmala et al., 2012). Each DMPS consists primarily of a differential mobility analyser (DMA) and a condensation particle counter (CPC). The sample air passes through a common bipolar diffusion charger, where aerosol particles are brought to a thermal charge equi- librium. Subsequently, the sample stream is divided into two to be directed to individual DMPSs, where aerosol particles are size segregated in the DMA by changing the voltage stepwisely and then counted in the CPC. The DMPS covered 3-500 nm until December 2004, after which the size range was expanded to $3-1000 \mathrm{~nm}$. The determination of the CS was conducted following the method presented by Kulmala et al. (2012). CS accounts for the loss rate of vapours due to condensational uptake by aerosol particles in the atmosphere (Kulmala et al., 2001).

The snow cover depth was measured manually on a weekly basis on seven different locations at the SMEAR II station. Measurements on soil temperature and soil volumetric water content were described by Pumpanen et al. (2003) and Ilvesniemi et al. (2010). Only the organic horizon data ( $5 \mathrm{~cm}$ depth, above the mineral layer; Pumpanen et al., 2003) were used in this work. The organic horizon is in direct contact with the atmosphere, the condition of which exerts the primary influence on radon exhalation. The ambient relative humidity and air temperature data were taken from the mast measurement at 16 and $4.2 \mathrm{~m}$, respectively. More detailed description of the mast instrumentation can be found from the home page of the measurement site (http://www. atm.helsinki.fi/SMEAR/index.php/smear-ii/measurements).

\subsection{Ionising capacity}

The ionising capacity $(Q)$ is defined as the potential maximum amount of ion pairs produced per unit time in a unit volume upon ionisation by ionising radiation in the atmosphere. The ionising capacity in this work was determined on the basis of the assumption that $34 \mathrm{eV}$ is needed for the production of an ion pair in the air. The energy released by ${ }^{222} \mathrm{Rn}$ and its short-lived progeny during alpha and beta decay were taken into consideration. The contributions from actinon $\left({ }^{219} \mathrm{Rn}\right)$ and thoron $\left({ }^{220} \mathrm{Rn}\right)$ were excluded in our study, because they are present in trace amounts naturally and have remarkably shorter half-lives $(3.96 \mathrm{~s}$ for actinon and $55.6 \mathrm{~s}$ for thoron) than ${ }^{222} \mathrm{Rn}$, which hardly permit them enough time to migrate out of the ground, especially in the case of actinon. Frozen ground and snow cover could substantially cease the transportation of thoron to the atmosphere during cold months. Even the vegetation reduces the flux of thoron from the ground to the surface air (Mattsson et al., 1996). Besides, Laakso et al. (2004) found only little contribution by thoron in the SMEAR II station to the overall radon activity. For ${ }^{222} \mathrm{Rn}$, the decay mode and energy accounted for the ionising capacity conversion are listed in Table 1 . The minor gamma fraction from the ${ }^{222} \mathrm{Rn}$ decay was assumed to be detectable by the gamma spectrometer. Therefore, the data obtained by the gamma spectrometer could be considered to represent the total gamma radiation, including the terrestrial fraction, the cosmic fraction and the fraction from radon decay. In addition, the gamma spectrometer also accounts ionising energy from muons. 
Table 1. Decay modes and energy of ${ }^{222} \mathrm{Rn}$ and its short-lived progeny taken into account in the ionising capacity determination. Decay partitioning is accounted in defining the weighted average decay energy. The data are extracted from the National Nuclear Data Centre of Brookhaven National Laboratory (http://www.nndc. bnl.gov/chart/).

\begin{tabular}{llr}
\hline Nuclide & Decay mode & $\begin{array}{r}\text { Weighted average } \\
\text { decay energy }(\mathrm{keV})\end{array}$ \\
\hline${ }^{222} \mathrm{Rn}$ & $\alpha(100 \%)$ & 5589 \\
${ }^{218} \mathrm{Po}$ & $\alpha(99.98 \%)$ & 6001 \\
${ }^{214} \mathrm{~Pb}$ & $\beta^{-}(100 \%)$ & 225 \\
${ }^{214} \mathrm{Bi}$ & $\beta^{-}(100 \%)$ & 642 \\
${ }^{214} \mathrm{Po}$ & $\alpha(100 \%)$ & 7687 \\
\hline
\end{tabular}

The conversion from the activity concentration $\left(\mathrm{Bq} \mathrm{m}^{-3}\right)$ to the ionising capacity $\left(\mathrm{cm}^{-3} \mathrm{~s}^{-1}\right)$ is straightforward, when the amount of energy released during the radioactive decay is known. The conversion from total dose rate (DR, $\mu \mathrm{Sv} \mathrm{h}^{-1}$ ) to the ionising capacity $\left(\mathrm{cm}^{-3} \mathrm{~s}^{-1}\right)$ is described by the following equation:

$Q_{\gamma}=\frac{\mathrm{DR} \cdot \rho_{\mathrm{air}}}{W}$,

where $W$ is the amount of energy needed for the generation of an ion pair in the air (assumed to be $34 \mathrm{eV}$ ) and $\rho_{\text {air }}$ is the density of air, which can be derived from the ideal gas law.

For conciseness and clarity, hereafter the ionising capacity results from the alpha and beta decay of ${ }^{222} \mathrm{Rn}$ and its shortlived daughter nuclides is denoted as the radon ionising capacity $\left(Q_{\mathrm{Rn}}\right)$ and the ionising capacity from total dose rates recorded by the gamma spectrometer as the gamma ionising capacity $\left(Q_{\gamma}\right)$.

\section{Results and discussions}

\subsection{Seasonal and diurnal patterns in the natural ionising capacity}

The natural ionising capacity has generally the same dynamical variations as ionising radiation, from which the ionising capacity was derived. A decline in the gamma ionising capacity was seen in the seasonal profile prior to the lowest value $\left(4.5 \mathrm{~cm}^{-3} \mathrm{~s}^{-1}\right)$ reached in March (Fig. 2), which corresponded typically to the maximum accumulation of snow on the ground. After a rapid recovery in April, the median gamma ionising capacity fluctuated at around $9.5 \mathrm{~cm}^{-3} \mathrm{~s}^{-1}$ during the rest of the year. The median radon ionising capacity varied in the range of $0.3-4.1 \mathrm{~cm}^{-3} \mathrm{~s}^{-1}$ and showed a seasonal behaviour very different from that of the gamma radiation. The minimum radon ionising capacity appeared in late spring after a gradual decrease since February. It climbed slowly back in summer and remained at a relatively moderate

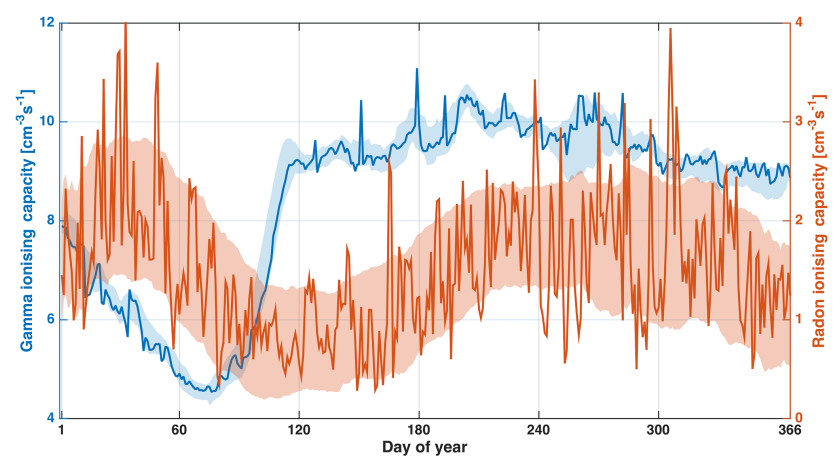

Figure 2. Seasonal patterns of radon and gamma ionising capacities as a function of day-of-year over the years 2003-2006. The radon ionising capacity was determined from the alpha and beta radioactivity associated with ${ }^{222} \mathrm{Rn}$ decay and the gamma ionising capacity from total gamma radiation. The data are presented as daily medians. Shaded bands are dedicated to outline the variabilities, expressed by standard deviations, of the data around their means determined using the moving average method.

level of around $1.7 \mathrm{~cm}^{-3} \mathrm{~s}^{-1}$ through autumn until the end of December.

The diurnal cycle in the ionising capacity originated mainly from the radon component and followed variations in the radon activity concentration presented by Chen et al. (2016), which was attributed to the mixing layer development. However, the contribution by gamma radiation shifted the relative levels of the ionising capacity from the seasonal pattern of the radon activity concentration shown by Chen et al. (2016). A clear diurnal cycle was observed in both spring and summer, with high ionising capacities found in the morning and low ones in the afternoon (Fig. 3). The ionising capacity was generally high in summer and autumn and low in spring and winter, with the median values being 8.9, $11.2,11.3$ and $8.7 \mathrm{~cm}^{-3} \mathrm{~s}^{-1}$ in spring (March-May), summer (June-August), autumn (September-November) and winter (December-February), respectively.

The share of radon ionising capacity in the total ionising capacity was in the range of 10-20\% (Fig. 4), with the lowest fraction obtained in spring and a progressive increase through the year reaching the highest share in winter. Interestingly, when separating the data according to the classification of NPF events defined by Dal Maso et al. (2005), low radon ionising capacities were found in association with NPF events. The statistical contribution of radon in ion pair production was below $10 \%$ on NPF days in all seasons (Fig. 4) and the median radon ionising capacities on NPF event days were typically one-third to half of those on nonevent days (Supplement Fig. S1 and Table 2). This observation is likely related to the fact that marine air masses from Arctic and North Atlantic oceans, which favour NPF (Nilsson et al., 2001), typically have a low radon content (Chen et al., 2016). Radon comes from the radioactive decay of radium. Since marine surface water has a significantly lower 


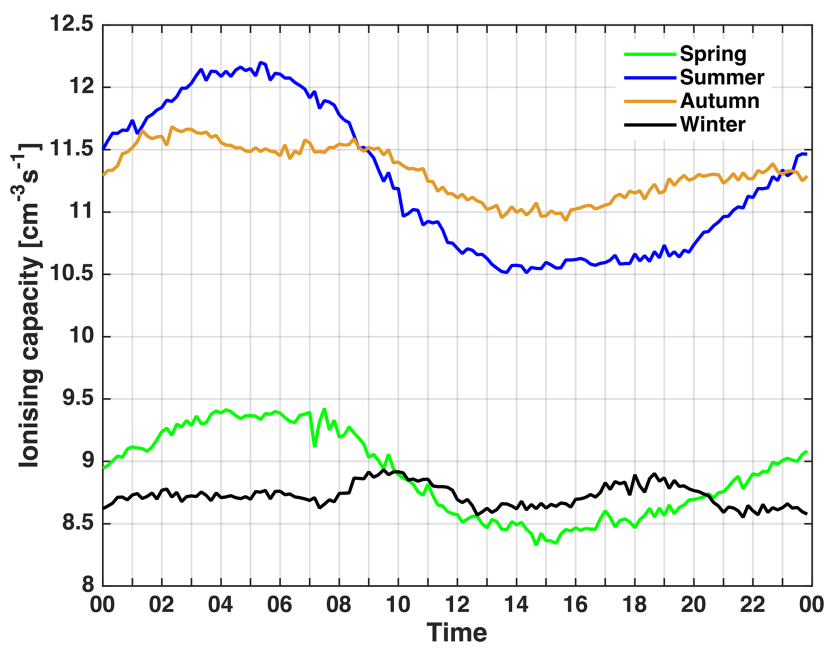

Figure 3. Diurnal cycles of the total ionising capacity presented as medians in different seasons in the years 2003-2006. Spring: March-May; summer: June-August; autumn: SeptemberNovember; winter: December-February.

Table 2. Median radon ionising capacity in $\mathrm{cm}^{-3} \mathrm{~s}^{-1}$ on new particle formation (NPF) event and non-event days in different seasons over 2003-2006.

\begin{tabular}{lrr}
\hline $\begin{array}{l}\text { NPF } \\
\text { classification }\end{array}$ & Event & Non-event \\
\hline Spring & 0.68 & 1.31 \\
Summer & 0.90 & 1.74 \\
Autumn & 0.99 & 1.8 \\
Winter & 0.56 & 1.96 \\
\hline
\end{tabular}

radium content than the continental surface layer (Wilkening and Clements, 1975), only minor amount of radon can be collected by air masses traversing over the ocean. Of the airborne ${ }^{222} \mathrm{Rn}, 99 \%$ originates from land and only $1 \%$ from the sea (Baskaran et al., 1993). In addition to the air mass aspect, the MLH might also play a role in bringing about the observation of low radon ionising capacities on NPF days as NPF typically occurs on warm and sunny days with clear skies, whereas non-event days are usually associated with the presence of clouds (Nieminen et al., 2015). Mixing reaches the top of a boundary layer on sunny and clear days, diluting atmospheric radon concentrations and resulting in a lower radon ionising capacity. On cloudy days, attenuated solar radiation enervates the convective development of the boundary layer, leading to the formation of a smaller mixing volume and thereby a higher radon ionising capacity. A statistical summary of the radon and gamma ionising capacities as well as the energy deposited by ionising radiation in the air is presented in Table 3.

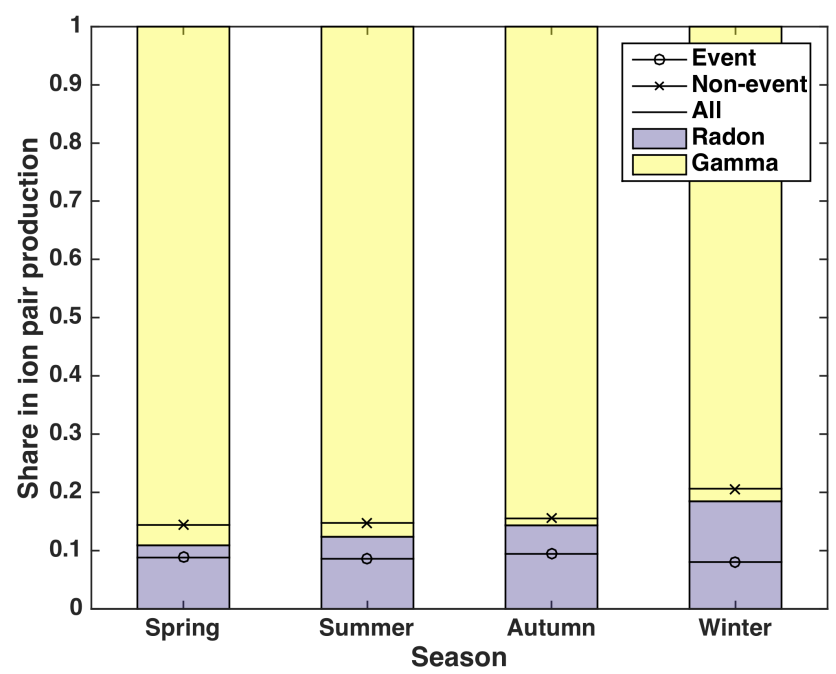

Figure 4. The relative importance of alpha and beta activities from ${ }^{222} \mathrm{Rn}$ and its short-lived daughter nuclides as well as total gamma radiation in air ion production. The division of the share between radon and gamma fractions on all days is indicated by a plain line, on new particle formation (NPF) event days by a line with an open circle and on non-event days by a line with a cross.

\subsection{Factors causing variability in the ionising capacity}

The seasonal and diurnal variations in the ionising capacity originate from features in ionising radiation, i.e. the atmospheric radon concentration and environmental gamma radiation. Presumably, the seasonality of the ionising capacity comes from both of the gamma and radon components, whereas the diurnal feature is primarily related to the dynamical response of radon as a result of the mixing layer evolution.

\subsubsection{Factors affecting the radon ionising capacity}

The atmospheric radon concentration, and consequently the derived radon ionising capacity, is affected by mixing layer dynamics, soil type, soil and meteorological conditions, long-distance transportation, etc. The atmospheric radon concentration is generally related to the mixing layer depth, which is also influenced by varying atmospheric conditions, in terms of the air temperature, wind speed, intensity of solar radiation, etc. These connections are further complicated by the arrival of continental air masses at the measurement site, which brings extra radon in addition to the local sources exhaled from the ground. Such aspects have been discussed in our earlier work (Chen et al., 2016).

Radon exhalation from the ground typically depends on the availability of ${ }^{226} \mathrm{Ra}$ - the parent nuclide of ${ }^{222} \mathrm{Rn}-$ the internal structure of mineral grains containing ${ }^{226} \mathrm{Ra}$, soil type, moisture condition, temperature and ambient pressure (Ashok et al., 2011; Lewis et al., 1987; Nazaroff, 1992; Stranden et al., 1984). ${ }^{226} \mathrm{Ra}$ typically decays into ${ }^{222} \mathrm{Rn}$ in- 
Table 3. Energy in $\mathrm{eV} \mathrm{m}^{-3} \mathrm{~s}^{-1}$ deposited in the air by total environmental gamma radiation $(E \gamma)$ and by alpha and beta activities from ${ }^{222} \mathrm{Rn}$ decay ( $E \mathrm{Rn}$ ) based on the 2003-2006 data. The gamma and radon ionising capacities $\left(Q \gamma\right.$ and $\left.Q_{\mathrm{Rn}}\right)$ in $\mathrm{cm}^{-3} \mathrm{~s}^{-1}$ were derived from the deposited energy assuming $34 \mathrm{eV}$ for the generation of one ion pair in the air. The statistical features of these data are presented by the five-number summary with two additional measures, the mean and standard deviation (SD).

\begin{tabular}{lrrrrrrr}
\hline & Min & $\begin{array}{r}\text { 25th } \\
\text { percentile }\end{array}$ & $\begin{array}{r}\text { 50th } \\
\text { percentile }\end{array}$ & $\begin{array}{r}\text { 75th } \\
\text { percentile }\end{array}$ & Max & Mean & SD \\
\hline$E_{\gamma}(\alpha$ and $\beta)$ & 0.769 & 242 & 314 & 338 & 544 & 295 & 72.3 \\
$E_{\mathrm{Rn}}$ & 0.145 & 28.6 & 50.3 & 79.5 & 284 & 58.1 & 38.8 \\
$Q_{\gamma}$ & 4.34 & 6.70 & 9.09 & 9.34 & 11.6 & 8.14 & 1.80 \\
$Q_{\mathrm{Rn}}$ & 0.00427 & 0.84 & 1.48 & 2.34 & 8.35 & 1.71 & 1.14 \\
\hline
\end{tabular}

side mineral grains. The release of these bonded radon atoms into pores among soil grains has been found favoured by the presence of some amount of water (Stranden et al., 1984). Nonetheless, a high moisture content in the soil can block the subsequent radon migration through soil pores into the atmosphere (Nazaroff, 1992). The radon's diffusion within and exhalation from the soil have a clear temperature dependency, as demonstrated by Chen et al. (2016). A similar relationship was also seen between the radon ionising capacity derived from the atmospheric radon concentration and the soil temperature: the radon ionising capacity increased with an increasing soil temperature (Fig. 5). A shallow mixing layer permits a small mixing volume, leading to a high radon ionising capacity, whereas a deep mixing layer promotes dilution. Accordingly, the lowest radon ionising capacities were observed in the highest MLH range. High radon ionising capacities, calculated as medians in $1^{\circ} \mathrm{C}$ soil temperature bins, were found at sub-zero soil temperatures with low MLHs, which are likely related to the reduced clogging by liquid water due to soil freezing and suppressed atmospheric mixing. Liquid water can remain in a frozen soil as thin films adsorbed on soil particles or in crevices and pores well below the freezing point (e.g. Spaans and Baker, 1996), which may still encourage the emanation of radon from soil grains. A further exhalation of radon into the atmosphere is probably achieved via frost-induced cracks.

In order to examine the impact of SWC on the radon ionising capacity, a soil temperature window $\left(T_{\text {soil }}>14^{\circ} \mathrm{C}\right)$ was selected when the MLH was restricted in the range of 1000$1500 \mathrm{~m}$, where the influence of soil temperature on the radon ionising capacity could be considered negligible (Fig. 6a). By zooming into this part of the data, there seemingly existed an effect of SWC, with the highest radon ionising capacity occurring at SWCs of around $0.20-0.25 \mathrm{~m}^{3} \mathrm{~m}^{-3}$ (Fig. 6b). This observation is consistent with the findings by Stranden et al. (1984), who showed that the presence of about $25 \%$ of water exerted the biggest enhancement in the exhalation rate of radon from soil samples. Further analysis into the SWC effect was performed by normalising the radon ionising capacity with proxies derived from MLH, soil temperatures and wind direction to minimise the influences of these

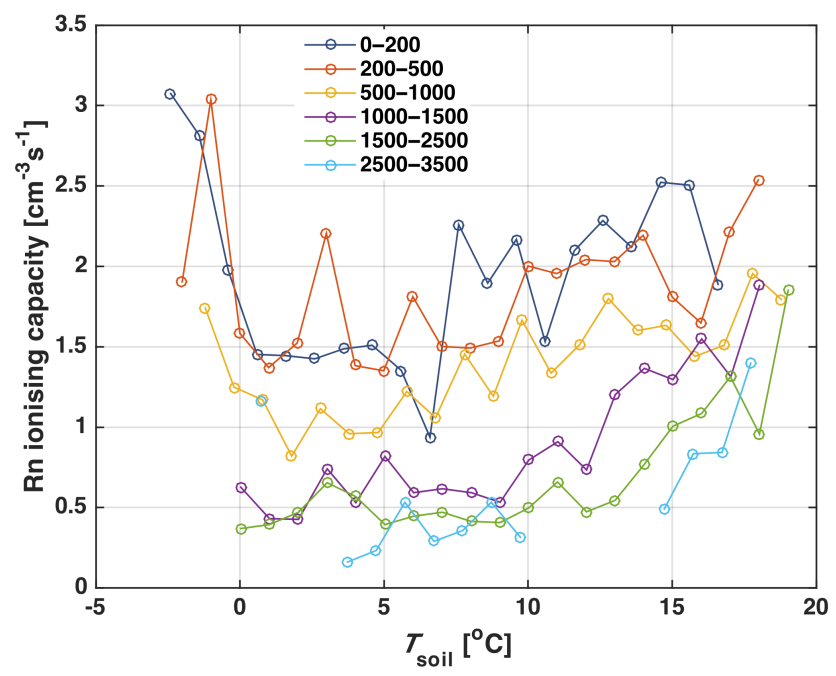

Figure 5. The median radon ionising capacity as a function of the soil temperature in $1^{\circ} \mathrm{C}$ bins. Lines are colour-coded by mixing layer height $(\mathrm{MLH})$ intervals.

factors. However, no systemic pattern was isolated between the radon ionising capacity and SWC for a supportive interpretation to be drawn upon. Besides, although RH has been reported as an influencing factor for radon exhalation (Ashok et al., 2011), no clear correlation between the radon ionising capacity and RH was found based on our dataset after ruling out the variability in the radon ionising capacity brought by MLH, temperature and wind.

\subsubsection{Factors affecting the gamma ionising capacity}

In comparison with the radon ionising capacity accounting for alpha and beta emissions of radon decay, the gamma ionising capacity exhibits a simpler pattern. Little diurnal variations exist in the total gamma radiation and therefore in the derived gamma ionising capacity. However, occasionally high gamma radiation is perceivable during rain events on a temporary basis, generally of about $2 \mathrm{~h}$. Such observations are typically ascribed to gamma emissions of the washed-out short-lived progeny of radon (Brunetti et al., 2000; Dwyer 

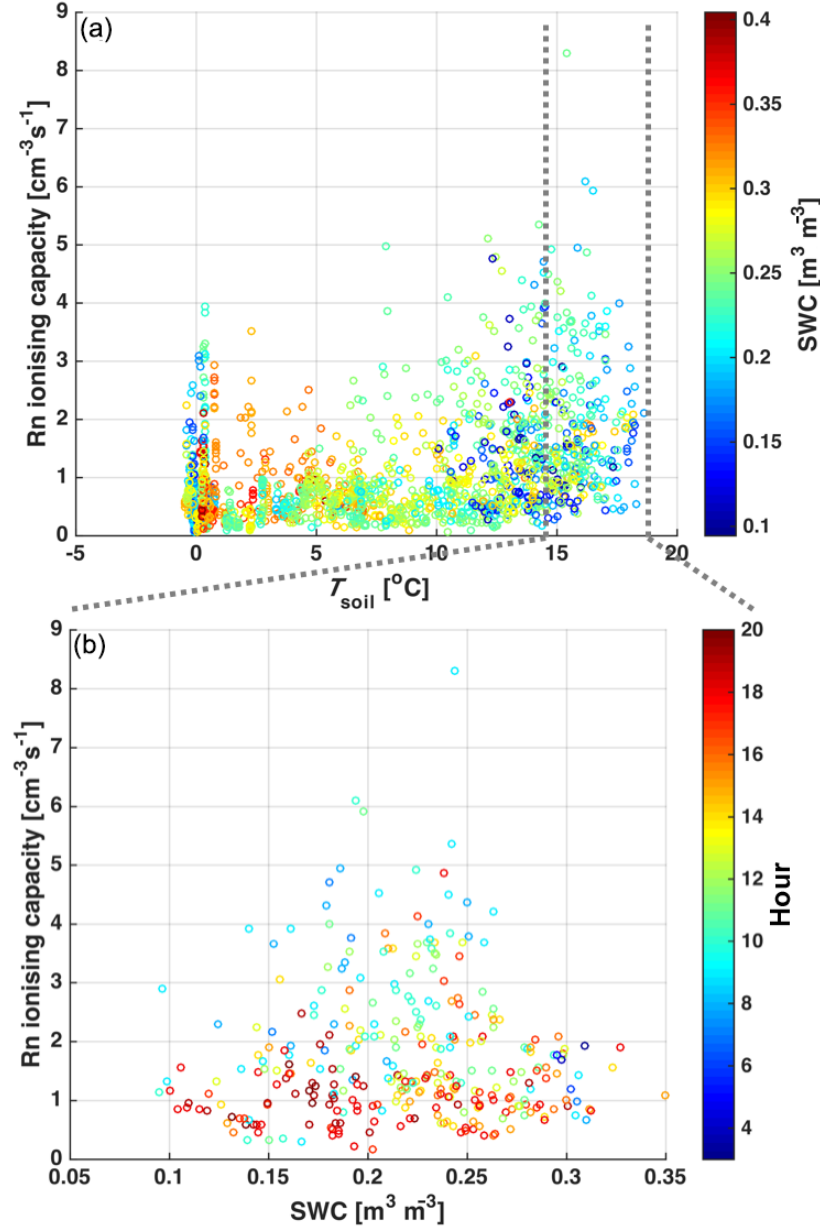

Figure 6. The effect of soil conditions on the radon ionising capacity. (a) Radon ionising capacities vs. soil temperatures $\left(T_{\text {soil }}\right)$ in the MLH range of 1000-1500 m with soil water content (SWC) shown on the colour scale. Hourly data are presented for 2003-2006 with data in 2004 excluded. According to Ilvesniemi et al. (2010), the quality of SWC data in 2004 was not acceptable. (b) Radon ionising capacities vs. SWCs for soil temperatures larger than $14^{\circ} \mathrm{C}$.

et al., 2012; Paatero and Hatakka, 1999). As for the seasonal cycle, the low gamma ionising capacity in winter results from the attenuation effect of snow cover on the terrestrial fraction of gamma radiation. An exponential reduction was typically seen in the gamma ionising capacity along with snow cover thickening (Fig. 7). A similar feature has been reported on the relationship between snow water equivalents and gamma dose rates for two other Finnish measurement sites in Sodankylä $\left(67^{\circ} 22^{\prime} \mathrm{N}, 26^{\circ} 39^{\prime} \mathrm{E}\right)$ and Tikkakoski $\left(62^{\circ} 24^{\prime} \mathrm{N}, 25^{\circ} 40^{\prime} \mathrm{E}\right)$ (Hatakka et al., 1998; Paatero et al., 2005). According to Paatero et al. (2005), the constant term in the exponential fitting to the measured snow depth data, which is about $3 \mathrm{~cm}^{-3} \mathrm{~s}^{-1}$, could represent an approximation of the contribution by cosmic radiation to the ionising capacity. A rate of $2 \mathrm{~cm}^{-3} \mathrm{~s}^{-1}$ has been generally accepted as the ionisation rate of cosmic radiation for the production of

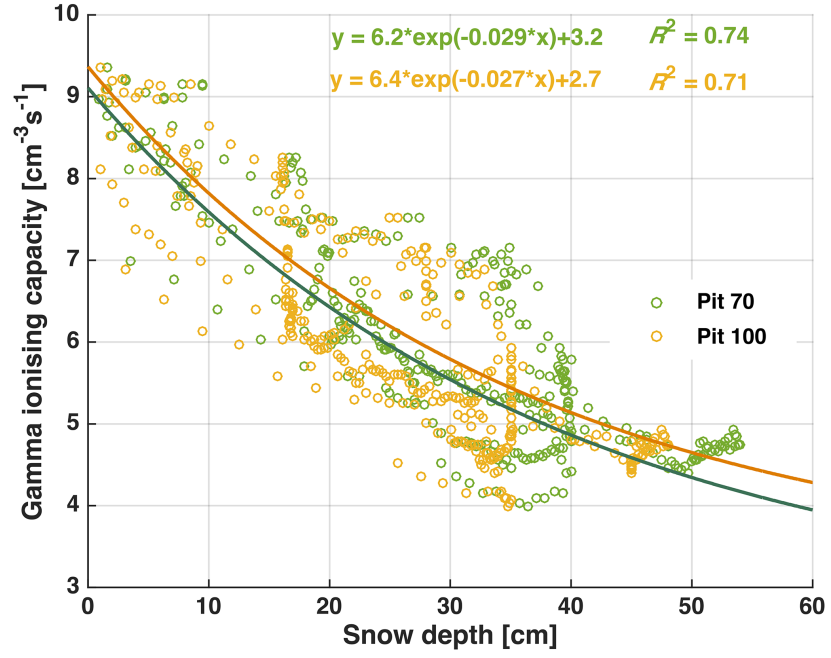

Figure 7. The attenuation effect of total gamma radiation by snow cover for the years 2003-2006. Pit 70 and 100 are two measurement points of snow cover depth. Exponential fittings were made with the goodness of fit denoted as $R^{2}$. The $95 \%$ confidence bounds for the constant term are [2.2 4.1] and [1.3 4.0] for pit 70 and pit 100, respectively.

small ions at sea level (Hensen and van der Hage, 1994). The cosmic radiation contribution to the ionising capacity determined from our measured total dose rates with the exponential fittings was close to this value. The discrepancy comes likely from uncertainties involved in the mathematical fitting and measurement including calibration. Minor contribution might originate from spatial variations in the cosmic radiation ionisation rate and solar activity influence.

\subsection{Ionising radiation and observed air ions}

Cluster ions are produced from primary and more complex molecular ions via their attachment to pre-existing small neutral clusters and the growth by vapour uptake. Molecular ions include both primary ions and those originating from the fraction of primary ions that have survived from the recombination or other sinks, and they are therefore in a close linkage with the ionising capacity. However, due to technical limitations, no reliable measurement can be carried out to acquire the concentration of molecular ions. Ions in the cluster size range $(0.8-1.7 \mathrm{~nm})$ are the smallest detectable air ion group based on the current counting technology. Since the formation of these ions are directly related to the dynamics of molecular ions and, to certain extent, to the ionising capacity, the focus in this section is the analysis of variations in the air ion concentration of the cluster size range in association with the ionising capacity. 


\subsubsection{Patterns in the ionising capacity and cluster ion concentration}

The cluster ion concentration exhibited some degree of association with the ionising capacity (Fig. 8). The median cluster ion concentration showed little diurnal variations during the cold months: from January to March, it remained at a low level (Fig. 8a), with a median of $513 \mathrm{~cm}^{-3}$. Clear diurnal cycles were discernible between April and October in cluster ions, while simultaneously the magnitude of diurnal variations in the median ionising capacity became distinguishable. On average, cluster ion concentrations were high during darker hours and low during brighter hours, which were aligned with the general feature seen in the ionising capacity (Figs. 3 and 8b), especially during the growth season of vegetation (May-August).

The enrichment in the median cluster ion concentration in the evening between May and August occurred typically a few hours ahead of the recovery of the median ionising capacity (Fig. 8). Such increases in cluster ion concentrations could result from either an augmentation in the production or a recession in the consumption or sink of these ions. In the former case, a balance between electric charge production and acquisition is re-established towards a higher production of cluster ions. Typically, this can be achieved via either a promotion in the production of electric charges or an enhancement in the charge acquisition. However, since no remarkable increase in the ionising capacity was observed, when cluster ion concentrations started to increase (Fig. 8), the production of cluster ions could be attributed to an enhancement in the charge acquisition. For the formation of cluster ions, the charge acquisition may occur at three stages: (a) prior to clustering via the formation of molecular ions from primary ions, (b) during the actual clustering process from both primary ions and molecular ions and (c) after clustering via the charge uptake from both primary ions and molecular ions. Recombination consumes part of these acquired charges, leaving the rest retained eventually in the form of cluster ions. In the latter case, certain removal processes of ions from the cluster size range are inhibited, which can be either the growth of cluster ions to sizes bigger than $1.7 \mathrm{~nm}$ or the loss of cluster ions by the attachment to bigger particles. All of these mechanisms, however, are manipulated primarily by atmospheric conditions. Atmospheric conditions, such as the temperature and relative humidity, can directly influence the rate of clustering and growth. Nonetheless, they also modify atmospheric compositions via the production of functional vapours involved in clustering or growth and via altering the availability of precursor gases of these vapours. As a consequence, these phenomena, seen in Fig. 8, are likely brought by a synergy of complicated atmospheric dynamic processes.

Although high ionising capacities were found in the morning, on average the morning cluster ion concentration was not so high as the evening level during the relatively warm months between April and October (Fig. 8a). Especially in autumn months, the enhancement in air ion production from the high morning ionising capacity was not reflected in the cluster ion concentration. Such observations may result from the cluster formation process becoming inferior to the preferred particle growth due to photochemical processes, while facing the dilution led by the expansion of the mixing volume. Autumn was the second peak period for the occurrence of NPF events at the SMEAR II station after spring (Nieminen et al., 2014). The dissimilar autumn and spring patterns in the cluster ion concentration originate likely from differences in atmospheric conditions and vapour sources. For example, spring UVA radiation intensities are higher than the autumn ones, while the RH shows an opposite behaviour (Lyubovtseva et al., 2005). Biogenic VOC emissions have a strong seasonality (Hakola et al., 2012; Tarvainen et al., 2005), which is reflected in their atmospheric concentrations. Hakola et al. (2012) demonstrated that monoterpenes tend to dominate VOCs in late summer and autumn, while aromatic hydrocarbons dominate in spring and early summer. Sesquiterpene emissions and concentrations were found to be high in late summer and autumn (Hakola et al., 2012; Tarvainen et al., 2005, 2007).

\subsubsection{Variations in cluster ion concentrations in sub-size ranges}

Ion concentrations in different sub-size ranges $(0.8-1,1-$ 1.2 and $1.2-1.7 \mathrm{~nm}$ ) of cluster sizes showed distinct patterns (Fig. 9). While the positive polarity dominated the overall cluster ion concentration, more negative ions were seen in the first two sub-size ranges $(0.8-1$ and $1-1.2 \mathrm{~nm})$. The former results from the electrode effect of the negatively charged Earth surface, which repels negative ions in its vicinity, and it is a well-known phenomenon in the atmospheric electricity community (Harrison and Carslaw, 2003; Israël, 1970; Tinsley, 2008; Wilson, 1921). The latter agrees with observations that generally negative ions possess higher mean mobility than positive ions (Dhanorkar and Kamra, 1992; Hõrrak, 2001; Israël, 1970); i.e. on average, negative ions are of smaller sizes than positive ions. Ion concentrations of $0.8-1 \mathrm{~nm}$ were found to be the lowest (around $100 \mathrm{~cm}^{-3}$ ) in all seasons. There was a difference of $150-200 \mathrm{~cm}^{-3}$ between the concentrations of $0.8-1 \mathrm{~nm}$ ions and $1-1.2 \mathrm{~nm}$ ions through all seasons in both polarities, with a larger difference observed in summer and smaller in winter. A more pronounced seasonality was observed for $1.2-1.7 \mathrm{~nm}$ ions, with the summer concentrations being the highest and winter concentrations being the lowest.

Slight diurnal patterns were found in $0.8-1$ and $1-1.2 \mathrm{~nm}$ ions. The $0.8-1 \mathrm{~nm}$ ion concentration showed features similar to those in the ionising capacity (Figs. 9 and 3), being high in the morning and low in the afternoon. This observation possibly indicates that the dominant population in the size range of $0.8-1 \mathrm{~nm}$ are molecular ions, which have not 
(a)

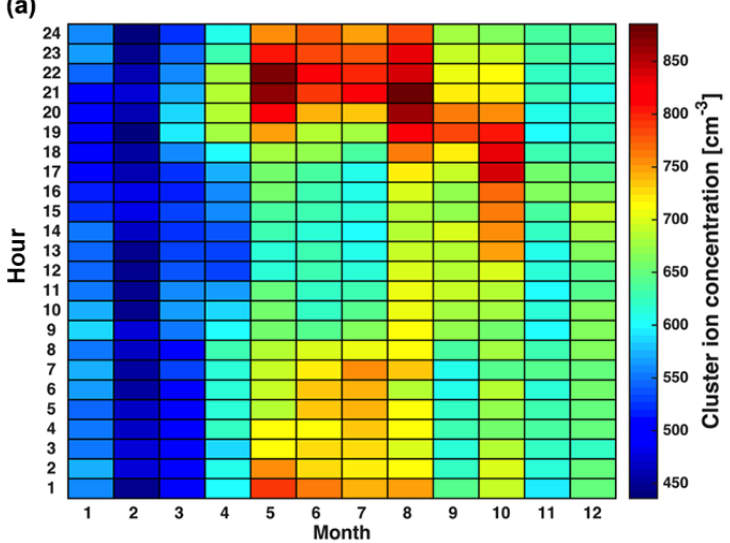

(b)

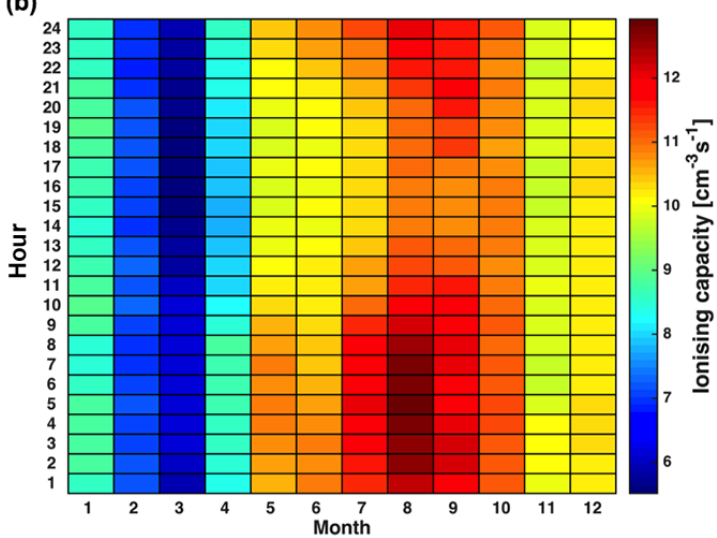

Figure 8. Median variations in (a) the mean cluster $(0.8-1.7 \mathrm{~nm})$ ion concentrations of negative and positive polarities measured by a balanced scanning mobility analyser (BSMA) and (b) the total ionising capacity over the years 2003-2006. Hourly medians were calculated for the whole measurement period from the 10 min measurement data prior to the processing of median values for each month as a vector of hour-of-day.

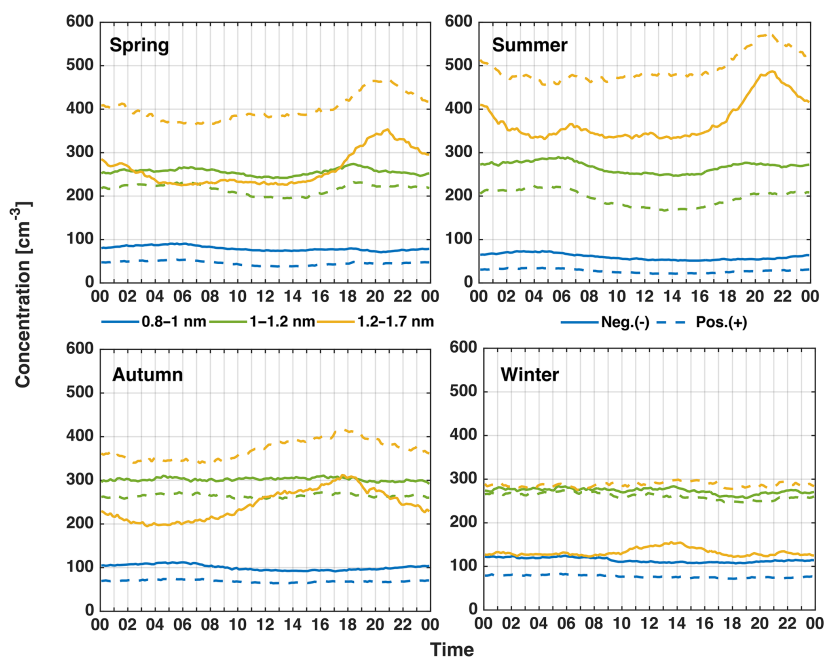

Figure 9. Median seasonality of the cluster ion concentration in $0.8-1,1-1.2$ and $1.2-1.7 \mathrm{~nm}$ ranges over the years $2003-2006$. Negative ion concentrations are depicted by the solid line and positive ion concentrations by the dash line.

been heavily influenced by dynamical processes of cluster formation and therefore retained the characteristics of primary ions. The seasonal pattern of $1-1.2 \mathrm{~nm}$ ions was inconsistent with that of the ionising capacity. Two bumps existed in the concentration of $1-1.2 \mathrm{~nm}$ ions in spring and summer; they were found more separated in summer than in spring. However, no identifiable diurnal variation in the $1-1.2 \mathrm{~nm}$ ion concentration was seen in autumn; in winter, the $1-1.2 \mathrm{~nm}$ ion concentration showed only a small valley in the late afternoon. For $1.2-1.7 \mathrm{~nm}$, which usually is the size range of critical clusters (Kulmala et al., 2012, 2013; Lange et al., 1996; Sipilä et al., 2010), clearer variations could be iden- tified. In all the seasons, a peak close to the sunset, evolving from noon in winter to late evening (21:00) in summer, was observed.

\subsubsection{Ionising capacities vs. $0.8-1 \mathrm{~nm}$ ions}

The ionising capacity contains radon and gamma fractions, both of which were observed to have the capability to promote the production of $0.8-1 \mathrm{~nm}$ ions (Fig. 10). The radon ionising capacity showed a slightly better correlation with the negative $0.8-1 \mathrm{~nm}$ ion concentration than with the positive polarity. Along with the increase in the radon ionising capacity, more of the $0.8-1 \mathrm{~nm}$ ions were detected, but the degree of dispersion intensified in the correlation plots (Figs. 10a and S2). This dispersion could come from a joint effect of the temperature $(T)$, moisture and background aerosol scavenging. Higher $0.8-1 \mathrm{~nm}$ ion concentrations were typically observed during darker hours (Fig. 8a) when the mixing layer is thin and photochemical processes restricted, possibly because the freshly formed $0.8-1 \mathrm{~nm}$ ions are confined in a smaller mixing volume and the production of vapours capable of growing small clusters becomes insufficient to support the growth of these ions out of the size range in question. According to Duplissy et al. (2016) and Kirkby et al. (2011), lower temperatures favour cluster formation in the atmosphere. However, since dark conditions prohibit the further growth of the newly formed clusters, a build-up of 0.8-1 nm ions during the darker hours is likely enabled at low temperatures, resulting in the highest $0.8-1 \mathrm{~nm}$ ion concentrations at the lowest air temperatures in Fig. S2c and d.

At high radon ionising capacities, the $0.8-1 \mathrm{~nm}$ ion concentration, especially in the positive polarity, dropped to a medium level in winter months under moist conditions (Fig. 10a-d). This observation might be related to the proton affinity of water molecules $\left(\mathrm{H}_{2} \mathrm{O}\right)$, which assigns $\mathrm{H}_{2} \mathrm{O}$ the 

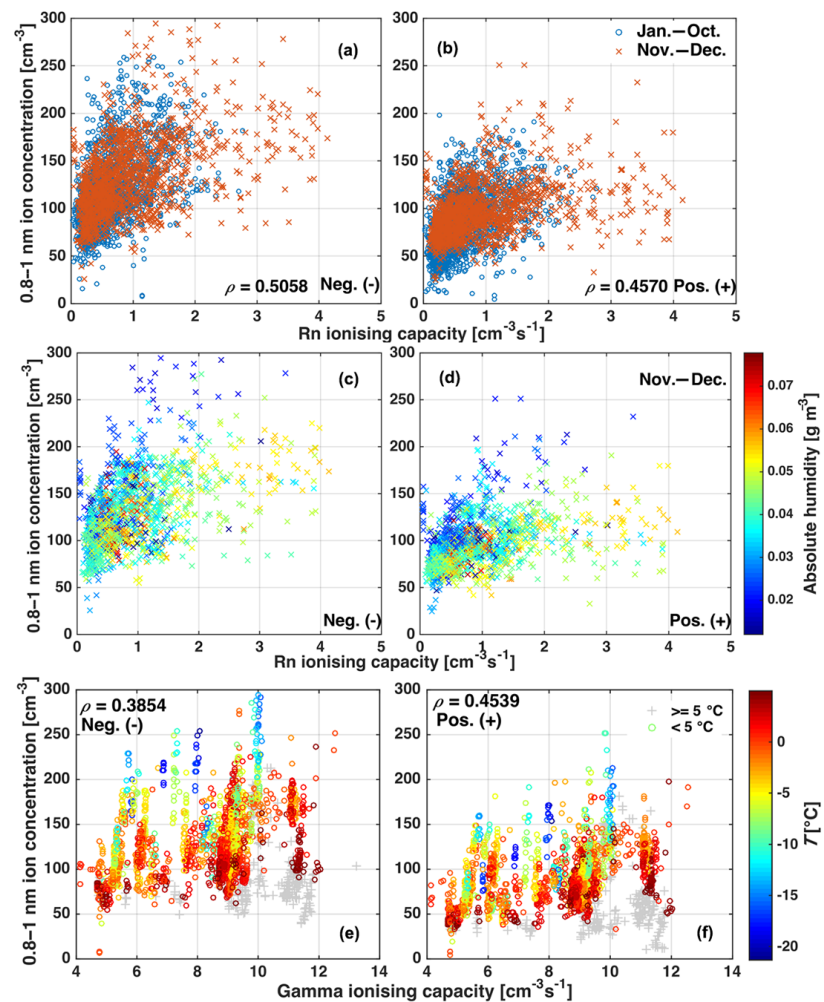

Figure 10. Relationship between the hourly ionising capacity and the $0.8-1 \mathrm{~nm}$ ion concentration when the condensation sink (CS) is below $0.001 \mathrm{~s}^{-1}$. Upper panels (a, b): radon ionising capacities vs. $0.8-1 \mathrm{~nm}$ ion concentrations for January-October (circle) and for November-December (cross). Middle panels $(\mathbf{c}, \mathbf{d})$ : radon ionising capacities vs. $0.8-1 \mathrm{~nm}$ ion concentrations with absolute humidity on the colour scale for November-December. Lower panel: gamma ionising capacities vs. $0.8-1 \mathrm{~nm}$ ion concentrations with air temperature $(T)$ on the colour scale. The Spearman's rank correlation coefficients $(\rho)$ in the upper panel were determined using all available data and those in the lower panel were determined between the gamma ionising capacity and the $0.8-1 \mathrm{~nm}$ ion concentration, when the $T$ was below $5^{\circ} \mathrm{C}$.

ability to bind positive charges. The formed cations may constitute a portion of hydronium ions $\left(\mathrm{H}_{3} \mathrm{O}^{+}\right)$, which are too small to be detected by the BSMA, resulting in the flatteningout of the $0.8-1 \mathrm{~nm}$ ion concentration. However, further experimental investigations are needed for the verification of this mechanism and quantification of its significance. As the CS can provide a measure of the condensational loss rate onto aerosol particles, the relatively high CS, as seen in Fig. S2e and f, could be an additional reason for the lower $0.8-1 \mathrm{~nm}$ ion production at high radon ionising capacities. For the negative polarity, a weak positive correlation between the radon ionising capacity and the $0.8-1 \mathrm{~nm}$ ion concentration was still perceptible at high radon ionising capacities, which may result from the ability of $\mathrm{H}_{2} \mathrm{O}$ to accommodate negative charges via the formation of clusters, even though it has negative electron affinity (Jalbout and Adamowicz, 2001;
Rienstra-Kiracofe et al., 2002). However, in addition to the CS effect, such dispersion could also originate from the variability in the stability of the anion clusters that is influenced, for example, by the geometric configuration of the cluster components as well as dipole properties of them.

The relationship between the gamma ionising capacity and $0.8-1 \mathrm{~nm}$ ion production was temperature dependent (Fig. 10e and f). When the $T$ was below $5^{\circ} \mathrm{C}$, the $0.8-$ $1 \mathrm{~nm}$ ion concentration showed a linear relation with the gamma ionising capacity. In addition, more $0.8-1 \mathrm{~nm}$ ions also tended to appear at lower temperatures, similar to the temperature effect seen on the relationship between the 0.8$1 \mathrm{~nm}$ ion concentration and the radon ionising capacity. A slightly higher correlation coefficient was found between the $0.8-1 \mathrm{~nm}$ ion concentration and the gamma ionising capacity in the positive polarity than that in the negative polarity (Fig. 10e and f). However, when the $T$ was above $5^{\circ} \mathrm{C}$, the linear relationship between the $0.8-1 \mathrm{~nm}$ ion concentration and the gamma ionising capacity was no longer identifiable: $0.8-1 \mathrm{~nm}$ ion concentrations remained at the lowest around $70 \mathrm{~cm}^{-3}$ in the negative polarity and $30 \mathrm{~cm}^{-3}$ in the positive polarity, regardless of the increase in the gamma ionising capacity.

The connections between the overall ionising capacity and the $0.8-1 \mathrm{~nm}$ ion concentration are reflected in their diurnal behaviour, with minor dissimilarities associated with varying atmospheric conditions and dynamical processes. The median diurnal variation of the $0.8-1 \mathrm{~nm}$ ion concentration was very similar to that of the ionising capacity in spring, summer and autumn: both the lowest median $0.8-1 \mathrm{~nm}$ ion concentration and the ionising capacity occurred typically at 14:00 when the mixing layer was fully developed (Fig. 11). In comparison with the ionising capacity, however, the $0.8-1 \mathrm{~nm}$ ion concentration seemed to follow more instantly the changes in the MLH. The reason behind this observation may be related to the fact that the diurnal variation in the ionising capacity is primarily contributed by radon decay emissions; for example, Chen et al. (2016) showed that the atmospheric radon concentration at near ground level does not respond immediately to mixing layer expansion or shrinkage. In contrast, $0.8-1 \mathrm{~nm}$ ion concentrations are related, in addition to the ionising capacity, to photochemical processes and availability of nucleating vapours influenced by solar intensity and atmospheric conditions.

In summer and spring, the median $0.8-1 \mathrm{~nm}$ ion concentration built up with the increase in the ionising capacity in the early morning before the solar irradiance started to intensify and the mixing layer to grow. The turbulence introduced by mixing layer development may assist the production of vapours for nucleation and growth from photochemical reactions, possibly initiating the growth of these $0.8-1 \mathrm{~nm}$ ions. As can be seen from Figs. 9 and S3, peak concentrations in the $1-1.2 \mathrm{~nm}$ size range occurred typically later than those in the $0.8-1 \mathrm{~nm}$ size range. Also, tiny bumps in $1.2-1.7 \mathrm{~nm}$ 

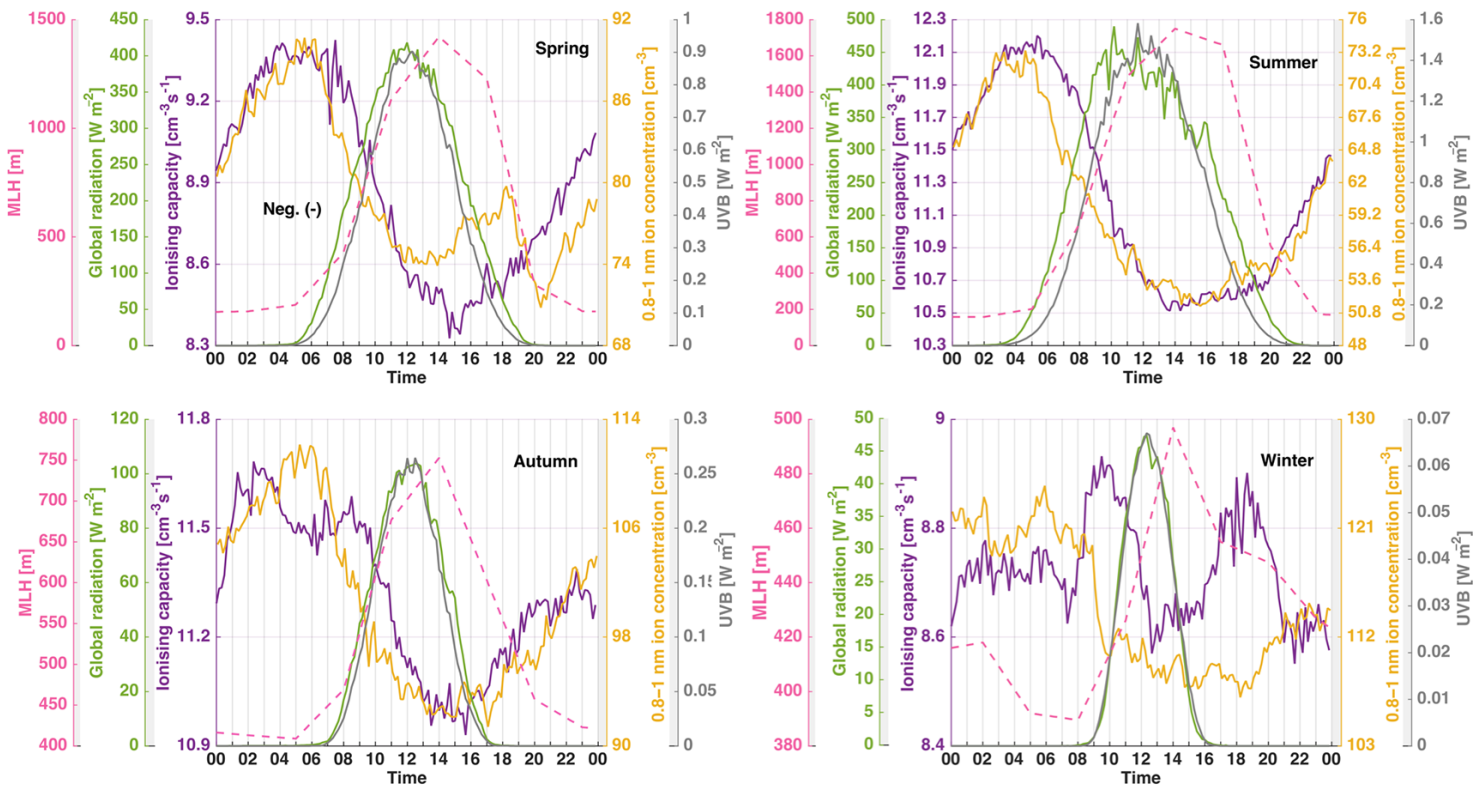

Figure 11. Diurnal patterns in median $0.8-1 \mathrm{~nm}$ negative and positive ion concentrations, ionising capacities, global and UVB radiation intensities as well as modelled mixing layer heights (MLH) in different seasons over 2003-2006.

ion concentrations could be discerned with some time lag at around 08:00-12:00 in spring and 05:00-07:00 in summer.

After the mixing layer had fully developed in spring, summer and autumn, there could be observed a transient boost in the $0.8-1 \mathrm{~nm}$ ion production (especially of the positive polarity) along with the shrinkage of the mixing layer, even prior to a clear recovery of the ionising capacity (Fig. 11). This observation may be attributed to the production of certain vapours that compete with the recombination process and other sink mechanisms for electric charges either via clustering or simple charge binding. Ionising radiation can potentially free a large number of electric charges, which would "sacrifice" themselves mostly in recombination, if not otherwise become detectable air ions. The survived electric charges take part in the formation of $0.8-1 \mathrm{~nm}$ ions mainly in the form of primary ions and molecular ions. Certain vapours can cluster among themselves around primary ions to form $0.8-1 \mathrm{~nm}$ ions. Charge-binding vapours, however, are able to take over charges from primary ions to form molecular ions. This charge transfer process may occur either via charge exchange ionisation or via chemical reactions between the vapour molecules and primary ions. Some of the molecular ions are possibly born with a size falling in the $0.8-1 \mathrm{~nm}$ size range. Ions in the $0.8-1 \mathrm{~nm}$ size range may additionally originate from (a) further growth of molecular ions via chemical reactions, (b) clustering of primary ions or molecular ions with nucleating vapours or among themselves or (c) charge uptake by small neutral clusters. Accordingly, the enhanced production of $0.8-1 \mathrm{~nm}$ ions after the complete development of the mixing layer, seen in Fig. 11, may be related to changes in the availability of nucleating or charge-binding vapours, altered likely by atmospheric conditions and mixing volume reduction.

Although the ionising capacity continued to increase ever since the recovery in the late afternoon, the enrichment of the $0.8-1 \mathrm{~nm}$ ion population ceased typically when little solar radiation was left (Fig. 11). At the same time, bursts in $1-1.2 \mathrm{~nm}$ ion concentrations and subsequently in $1.2-1.7 \mathrm{~nm}$ ion concentrations were seen (Figs. 9 and S3), which were probably linked to the nocturnal cluster formation events (Ehn et al., 2010; Lehtipalo et al., 2011; Mazon et al., 2016). The emergence of this phenomenon lies at the basis that the production rate of $0.8-1 \mathrm{~nm}$ ions by clustering or charge binding is overtaken by the consumption rate of them via either coagulation or condensational growth. The $1.2-1.7 \mathrm{~nm}$ ion concentration typically peaked nearly right after the die-out of photochemical reactions when dark hours came (Fig. S3). Concurrently, the $0.8-1 \mathrm{~nm}$ ion concentration started to increase again, as the ionising capacity intensified (Fig. 11).

\subsubsection{Role of ionising radiation in cluster ion formation}

There existed a weak relation between the total ionising capacity and the ion concentration of the whole cluster size (0.8-1.7 nm) range (Fig. 12). On NPF event days, the cluster ion concentration showed a relatively clear increase with the intensification of the ionising capacity (Fig. 12a and b). However, since the cluster ions are very small, they can preserve some properties of gaseous molecules and therefore may sink onto bigger particles. Consequently, corresponding to an ionising capacity value, the cluster ion concentration 


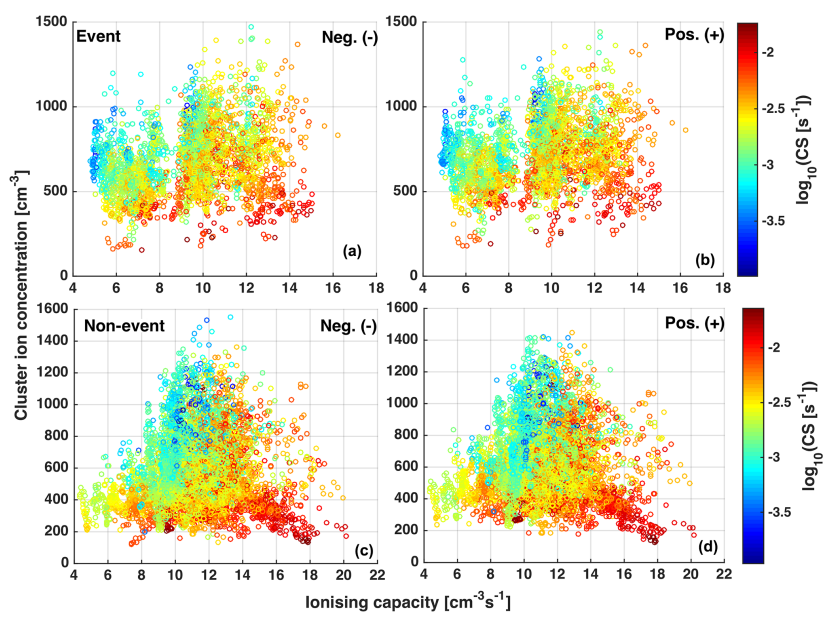

Figure 12. The $1 \mathrm{~h}$ cluster $(0.8-1.7 \mathrm{~nm})$ ion concentration as a function of the total ionising capacity on new particle formation event days (upper panel) and non-event days (lower panel), with the condensation sink (CS) indicated on the colour scale.

spanned over a wide range, with high cluster ion concentrations occurring at low CSs. On non-event days, however, the connection between the ionising capacity and the cluster ion concentration became even less identifiable, probably due to the fact that CSs on non-event days are typically higher than those on event days by a factor of 3.6 on average (Dal Maso et al., 2005). In addition to this, meteorological and atmospheric conditions are also more versatile on non-event days than on event days, because NPF events are usually localised in spring, but non-events are spread all over the year (Dal Maso et al., 2005; Nieminen et al., 2014).

By carefully setting constraints to focus on data obtained under relatively uniform conditions, it was possible to observe a clear relationship between the total ionising capacity and the whole cluster population (Fig. 13). A time window between 00:00 and 03:00 was selected to minimise the effect of diurnal variations. Since the value of CS is typically largest during night-time (Kulmala et al., 2013), the constraint on the CS was set to be below $0.002 \mathrm{~s}^{-1}$, instead of $0.001 \mathrm{~s}^{-1}$, in Fig. 13. No dependency of the cluster ion concentration on the CS or on the hour of the day was identified. As can be seen in Fig. 2, generally little variations in both radon and gamma ionising capacities existed between September and December, which therefore was chosen as the time window for the analysis. Furthermore, the wind direction was restricted between 280 and $30^{\circ}$ to shield the effect of radon transported from continental sources.

On both NPF event (Fig. 13a and b) and non-event (Fig. 13c and d) days, the cluster ion concentration grew with an increase in the ionising capacity. The dependency of the cluster ion concentration on the ionising capacity was weaker on non-event days than that on NPF event days. Higher ionising capacities were seen on non-event days, and correspondingly more cluster ions were detected on such days than on
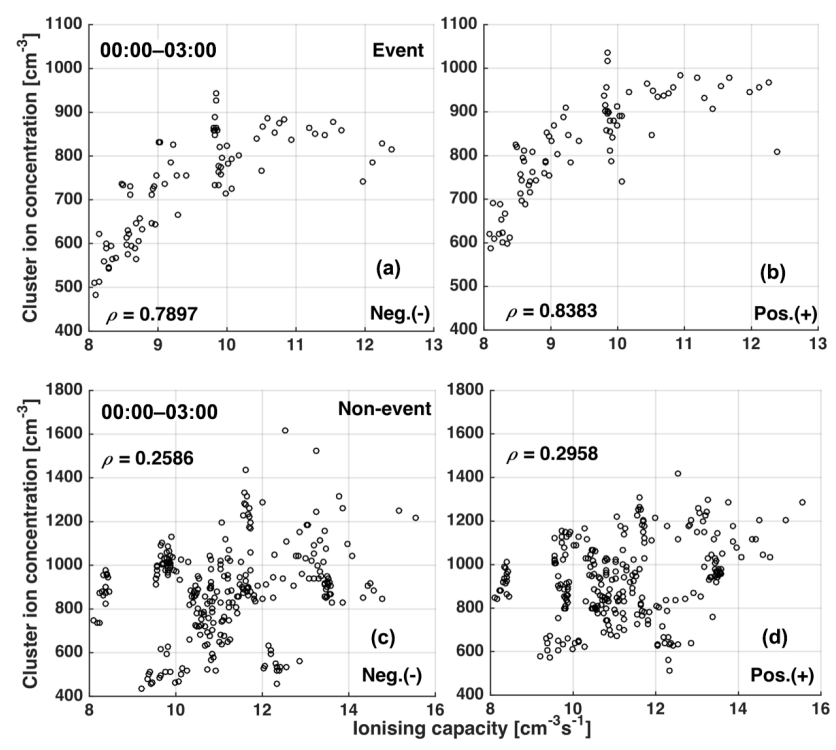

Figure 13. The cluster $(0.8-1.7 \mathrm{~nm})$ ion concentration as a function of the ionising capacity (radon ionising capacity + gamma ionising capacity) for selected data in the years 2003-2006, with Spearman's rank correlation coefficient $(\rho)$. The data were constrained on $(\mathbf{a}, \mathbf{b})$ event days and (c, d) non-event days in September-December between 00:00 and 03:00 with the wind direction between 280 and $30^{\circ}$ and the condensation sink (CS) below $0.002 \mathrm{~s}^{-1}$. No dependence of the cluster ion concentration on the CS or hour-of-day was identified. Also the snow season was screened out. The negative polarity is shown in $(\mathbf{a}, \mathbf{c})$ and the positive in $(\mathbf{b}, \mathbf{d})$.

event days. The cluster ion concentration tended to level out on event days at high ionising capacities for both polarities $\left(\geq 10.5 \mathrm{~cm}^{-3} \mathrm{~s}^{-1}\right.$ ) (Fig. 13a and b), implying that the formation process of cluster ions was not efficient enough to rescue charges from recombination. However, such a feature showed no trace on non-event days and also the cluster ion concentration was more dispersed as a function of the ionising capacity. The reason for these observations may be owing to the fact that NPF occurs on days with some certain combination of atmospheric conditions as well as physical and chemical processes, but high variability is involved in these parameters on non-event days. In addition, the better dependency of the cluster ion concentration on the ionising capacity observed on NPF event days than on non-event days may also imply that charges, after being produced via ionisation by ionising radiation, on NPF event days did not undergo significant transformations to become cluster ions. Therefore, the linkage between the cluster ion concentration and ionising capacity was traceable statistically. However, this connection was very poorly preserved on non-event days, possibly because, after being created, charges went through a too complicated series of modifications before reaching the cluster sizes. These observations may also provide some indirect measure of the relative duration of dynamic processes faced by newly formed charges before they become cluster ions 
under different atmospheric conditions: it might suggest that charges became cluster ions in a shorter timescale on NPF event days than on non-event days and, as a consequence, the cluster ions on NPF event days are enabled to retain some features in connection to ionising radiation.

\section{Conclusions}

In this work, diurnal and seasonal cycles in ionising radiation were presented and key influencing factors responsible for these features were overviewed in order to investigate how observed air ions respond to these variations and to improve our understanding on air ion formation. To assist the analysis, a term, ionising capacity, was introduced to capture patterns in ionising radiation. The ionising capacity was determined theoretically as the potential maximum production rate of ion pairs in the atmosphere by ionising radiation, based on the assumption that an ion pair is produced upon every $34 \mathrm{eV}$ energy dissipation of ionising radiation. The data used in this study were collected from ambient measurements from a boreal forest site in southern Finland during 2003-2006. In our analysis, the accounted ionising radiation is composed of energy from alpha and beta decays of ${ }^{222} \mathrm{Rn}$ and accompanying gamma radiation, energy contained in the gamma radiation from terrestrial origins as well as gamma radiation and muons released from the interactions between cosmic rays and air molecules. However, a portion of high-energy cosmic ray muons may be missing from our scope. Variations in the ionising capacity were primarily related to boundary layer development, soil conditions, snow accumulation and the origin of air masses.

Although ionising radiation is known to be responsible for air ion production, patterns in the measured air ion concentration in the cluster size range $(0.8-1.7 \mathrm{~nm})$ did not exhibit a highly comparability to those in the ionising capacity due to modifications of air ion properties exerted by different dynamical processes and chemical reactions during the evolution of charges in the atmosphere. Nevertheless, the connection of air ions to ionising radiation was seen for air ions detected in the lowest detected size band $(0.8-1 \mathrm{~nm})$ of the cluster size range $(0.8-1.7 \mathrm{~nm})$. The evolvement of these $0.8-$ $1 \mathrm{~nm}$ ions with time to larger sizes in the cluster size band was also identified, affirming the primary role of ionising radiation in the production of air ions in the lower atmosphere. However, atmospheric conditions, such as temperature, humidity and pre-existing aerosol particles, brought complications into this relationship. By carefully constraining data to conditions of a similar meteorology, seasonality, diurnality and amount of background aerosol particles, a strong dependency of total cluster ion concentrations on the ionising capacity was identified on NPF days. However, the linkage was not visible on non-event days. These observations may suggest that charges, after being born, underwent different processes on NPF days and non-event days and possibly indicate also that the transformation of newly formed charges to cluster ions occurred faster on NPF days than on non-event days. These results could help to advance our understanding on the role of ions in atmospheric new particle formation.

However, to obtain further insights into the fate of charges created by ionising radiation in the atmosphere, i.e. ion balance, and into the role of air ions in the atmospheric new particle formation process, it is crucial to understand the transformation process of electric charges into detectable air ions. For this purpose, knowledge on the number size distribution of air ions smaller than $0.8 \mathrm{~nm}$ is of necessity. Additionally, theoretical understanding on the formation mechanisms of cluster ions from molecular ions needs to be deepened. Conjointly, also advancing instrumental development for the detection of sub- $0.8 \mathrm{~nm}$ ions could be worth being brought onto the agenda.

\section{Data availability}

The aerosol particle and meteorological data used in this work are publicly accessible on the SmartSmear website (http://avaa.tdata.fi/web/smart/smear/) (SMEAR, 2016). The air ion and ionising radiation data are in the process to be implemented in the SmartSmear system. The MLH data were extracted from the European Centre for Medium-Range Weather Forecasts (ECMWF) Meteorological Archival and Retrieval System (MARS), Reading, UK (www.ecmwf.int) (ECMWF, 2016). All the data are also available upon direct request to the corresponding author.

\section{The Supplement related to this article is available online at doi:10.5194/acp-16-14297-2016-supplement.}

Acknowledgements. This work received funding support from the Academy of Finland Centre of Excellence (project no. 272041 and 1118615), European Union's Horizon 2020 research and innovation programme under grant agreement no. 654109 (ACTRIS-2) as well as the European Union Seventh Framework Programme (FP7/2007-2013 ACTRIS) under grant agreement no. 262254. Also the CRyosphere-Atmosphere Interactions in a Changing arctic Climate (CRAICC) project of the Nordic Centre of Excellence is acknowledged. The authors appreciate the valuable communication with Jaana Bäck, Pasi Kolari, Anne Hirsikko and Juha Hatakka.

Edited by: D. Spracklen

Reviewed by: two anonymous referees 


\section{References}

Aalto, P., Hämeri, K., Becker, E., Weber, R., Salm, J., MäKelä, J. M., Hoell, C., O’Dowd, C. D., Karlsson, H., Hansson, H.-C., VäKevä, M., Koponen, I. K., Buzorius, G., and Kulmala, M.: Physical characterization of aerosol particles during nucleation events, Tellus, 53B, 344-358, 2001.

Aplin, K. L. and Harrison, R. G.: A computer-controlled Gerdien atmospheric ion counter, Rev. Sci. Instrum., 71, 3037, doi:10.1063/1.1305511, 2000.

Ashok, G. V., Nagaiah, N., Shiva Prasad, N. G., and Ambika, M. R.: Study of radon exhalation rate from soil, Bangalore, south India, Radiat. Protect. Environ., 34, 235-239, 2011.

Baskaran, M., Coleman, C. H., and Santschi, P. H.: Atmospheric depositional fluxes of ${ }^{7} \mathrm{Be}$ and ${ }^{210} \mathrm{~Pb}$ at Galveston and College Station, Texas, J. Geophys. Res., 98, 20555, doi:10.1029/93jd02182, 1993.

Bennett, A. J. and Harrison, R. G.: Atmospheric electricity in different weather conditions, Weather, 62, 277-283, 2007.

Brunetti, M., Cecchini, S., Galli, M., Giovannini, G., and Pagliarin, A.: Gamma-ray bursts of atmospheric origin in the MeV energy range, Geophys. Res. Lett., 27, 1599-1602, doi:10.1029/2000g1003750, 2000.

Canton, J.: Electrical Experiments, with an Attempt to Account for Their Several Phaenomena; Together with Some Observations on Thunder-Clouds, Phil. Trans., 48, 350-358, 1753a.

Canton, J.: A letter to the right honourable the earl of macclesfield, president of the royal society, concerning some new electrical experiments, Phil. Trans., 48, 780-785, $1753 \mathrm{~b}$.

Carlson, P. and De Angelis, A.: Nationalism and internationalism in science: the case of the discovery of cosmic rays, Eur. Phys. J. H, 35, 309-329, doi:10.1140/epjh/e2011-10033-6, 2011.

Chen, X., Paatero, J., Kerminen, V.-M., Riuttanen, L., Hatakka, J., Hiltunen, V., Paasonen, P., Hirsikko, A., Franchin, A., Manninen, H. E., Petäjä, T., Viisanen, Y., and Kulmala, M.: Responses of the atmospheric concentration of radon-222 to the vertical mixing and spatial transportation, Boreal Environ. Res., 21, 299-318, 2016.

Crookes, W.: On Electrical Insulation in High Vacua, P. R. Soc. London, 28, 347-352, 1878.

Cumeras, R., Figueras, E., Davis, C. E., Baumbach, J. I., and Gracia, I.: Review on ion mobility spectrometry. Part 1: current instrumentation, Analyst, 140, 1376-1390, doi:10.1039/c4an01100g, 2015.

Dal Maso, M., Kulmala, M., Riipinen, I., Wagner, R., Hussein, T., Aalto, P. P., and Lehtinen, K. E. J.: Formation and growth of fresh atmospheric aerosols: eight years of aerosol size distribution data from SMEAR II, Hyytiälä, Finland, Boreal Environ. Res., 10, 323-336, 2005.

De Angelis, A.: Atmospheric ionization and cosmic rays: studies and measurements before 1912, Astropart. Phys., 53, 19-26, doi:10.1016/j.astropartphys.2013.05.010, 2014.

Dhanorkar, S. and Kamra, A. K.: Relation between electrical conductivity and small ions in the presence of intermediate and large ions in the lower atmosphere, J. Geophys. Res., 97, 2034520360, 1992.

Duplissy, J., Merikanto, J., Franchin, A., Tsagkogeorgas, G., Kangasluoma, J., Wimmer, D., Vuollekoski, H., Schobesberger, S., Lehtipalo, K., Flagan, R. C., Brus, D., Donahue, N. M., Vehkamäki, H., Almeida, J., Amorim, A., Barmet, P., Bianchi,
F., Breitenlechner, M., Dunne, E. M., Guida, R., Henschel, H., Junninen, H., Kirkby, J., Kürten, A., Kupc, A., Mättänen, A., Makhmutov, V., Mathot, S., Nieminen, T., Onnela, A., Praplan, A. P., Riccobono, F., Rondo, L., Steiner, G., Tome, A., Walther, H., Baltensperger, U., Carslaw, K. S., Dommen, J., Hansel, A., Petäjä, T., Sipilä, M., Stratmann, F., Vrtala, A., Wagner, P. E., Worsnop, D. R., Curtius, J., and Kulmala, M.: Effect of ions on sulfuric acid-water binary particle formation: 2 . Experimental data and comparison with QC-normalized classical nucleation theory, J. Geophys. Res.-Atmos., 121, 1752-1775, doi:10.1002/2015JD023539, 2016.

Dwyer, J. R., Schaal, M. M., Cramer, E., Arabshahi, S., Liu, N., Rassoul, H. K., Hill, J. D., Jordan, D. M., and Uman, M. A.: Observation of a gamma-ray flash at ground level in association with a cloud-to-ground lightning return stroke, J. Geophys. Res., 117, A10303, doi:10.1029/2012ja017810, 2012.

ECMWF: Boundary layer heights from the operative forecast model in use at the time by the European Centre for Medium-Range Weather Forecasts (ECMWF), available at: http://www.ecmwf. int/en/forecasts/datasets, last access: 14 November 2016.

Ehn, M., Junninen, H., Petäjä, T., Kurtén, T., Kerminen, V.-M., Schobesberger, S., Manninen, H. E., Ortega, I. K., Vehkamäki, H., Kulmala, M., and Worsnop, D. R.: Composition and temporal behavior of ambient ions in the boreal forest, Atmos. Chem. Phys., 10, 8513-8530, doi:10.5194/acp-10-8513-2010, 2010.

Ehn, M., Junninen, H., Schobesberger, S., Manninen, H. E., Franchin, A., Sipilä, M., Petäjä, T., Kerminen, V.-M., Tammet, H., Mirme, A., Mirme, S., Hõrrak, U., Kulmala, M., and Worsnop, D.: An instrumental comparison of mobility and mass measurements of atmospheric small ions, Aerosol Sci. Tech., 45, 522-532, doi:10.1080/02786826.2010.547890, 2011.

Fernandez-Garcia, J. and Fernandez de la Mora, J.: Measuring the effect of ion-induced drift-gas polarization on the electrical mobilities of multiply-charged ionic liquid nanodrops in air, J. Am. Soc. Mass Spectr., 24, 1872-1889, doi:10.1007/s13361013-0702-1, 2013.

Flagan, R. C.: History of electrical aerosol measurements, Aerosol Sci. Tech., 28, 301-380, doi:10.1080/02786829808965530, 1998.

Franklin, B.: A Letter of Benjamin Franklin, Esq; to Mr. Peter Collinson, F. R. S. concerning an Electrical Kite, Phil. Trans., 47, 565-567, 1751.

Gerdien, H.: Die absolute messung der specifischen leitfähigkeit und der dichte des verticalen leitungsstromes in der atmosphäre, Terrestrial Magnetism and Atmospheric Electricity, 10, 65-74, 1905.

Goldhagen, P.: Overview of aircraft radiation exposure and recent ER-2 measurements, Health Phys., 79, 526-544, 2000.

Hakola, H., Hellén, H., Hemmilä, M., Rinne, J., and Kulmala, M.: In situ measurements of volatile organic compounds in a boreal forest, Atmos. Chem. Phys., 12, 11665-11678, doi:10.5194/acp12-11665-2012, 2012.

Hari, P. and Kulmala, M.: Station for measuring ecosystematmosphere relations (SMEAR II), Boreal Environ. Res., 10, 315-322, 2005.

Harrison, R. G. and Carslaw, K. S.: Ion-aerosol-cloud processes in the lower atmosphere, Rev. Geophys., 41, 1012, doi:10.1029/2002rg000114, 2003. 
Hatakka, J., Paatero, J., Viisanen, Y., and Mattsson, R.: Variations of external radiation due to meteorological and hydrological factors in central Finland, Radiochemistry, 40, 534-538, 1998.

Hensen, A. and van der Hage, J. C. H.: Parameterisation of cosmic radiation at sea level, J. Geophys. Res., 99, 10693-10695, 1994.

Herbert, K. B. H.: John Canton - Pioneer investigator of atmospheric electricity, Weather, 52, 286-290, 1997.

Hewitt, G. W.: The charging of small particles for electrostatic precipitation, Trans. Am. Inst. Elect. Engr., 76, 300-306, 1957.

Hinds, W. C.: Aerosol technology: Properties, behavior, and measurement of airborne particles, 2 Edn., Wiley-Interscience, New York, 1999.

Hirsikko, A., Paatero, J., Hatakka, J., and Kulmala, M.: The ${ }^{222}$ Rn activity concentration, external radiation dose and air ion production rates in a boreal forest in Finalnd between March 2000 and June 2006, Boreal Environ. Res., 12, 265-278, 2007.

Hirsikko, A., Nieminen, T., Gagné, S., Lehtipalo, K., Manninen, H. E., Ehn, M., Hõrrak, U., Kerminen, V.-M., Laakso, L., McMurry, P. H., Mirme, A., Mirme, S., Petäjä, T., Tammet, H., Vakkari, V., Vana, M., and Kulmala, M.: Atmospheric ions and nucleation: a review of observations, Atmos. Chem. Phys., 11, 767798, doi:10.5194/acp-11-767-2011, 2011.

Hogg, A. R.: The intermediate ions of the atmosphere, Proc. Phys. Soc., 51, 1014-1027, 1939.

Hõrrak, U.: Air ion mobility spectrum at a rural area, $\mathrm{PhD}$, Institute of Environmental Physics, University of Tartu, Tartu, Estonia, 81 pp., 2001.

Ilvesniemi, H., Pumpanen, J., Duursma, R., Hari, P., Keronen, P., Kolari, P., Kulmala, M., Mammarella, I., Nikinmaa, E., Rannik, U. L., Pohja, T., Siivola, E., and Vesala, T.: Water balance of a boreal scots pine forest, Boreal Environ. Res., 15, 375-396, 2010.

Israël, H.: Atmospheric electricity, Vol. I, Israel Program for Scientific Translations, Jerusalem, 1970.

Jalbout, A. F. and Adamowicz, L.: Dipole-Bound Anions of Adenine-Water Clusters. Ab Initio Study, J. Phys. Chem. A, 105, 1033-1038, 2001.

Jesse, W. and Sadaukis, J.: Absolute energy to produce an ion pair by beta particles from $\mathrm{S}^{35}$, Phys. Rev., 107, 766-771, doi:10.1103/PhysRev.107.766, 1957.

Junninen, H., Ehn, M., Petäjä, T., Luosujärvi, L., Kotiaho, T., Kostiainen, R., Rohner, U., Gonin, M., Fuhrer, K., Kulmala, M., and Worsnop, D. R.: A high-resolution mass spectrometer to measure atmospheric ion composition, Atmos. Meas. Tech., 3, 10391053, doi:10.5194/amt-3-1039-2010, 2010.

Junninen, H., Duplissy, J., Ehn, M., Sipilä, M., Kangasluoma, J., Franchin, A., Petäjä, T., Manninen, H. E., Kerminen, V.M., Worsnop, D., and Kulmala, M.: Measuring atmospheric ion bursts and their dynamics using mass spectrometry, Boreal Env. Res., 21, 207-220, 2016.

Kirkby, J., Curtius, J., Almeida, J., Dunne, E., Duplissy, J., Ehrhart, S., Franchin, A., Gagne, S., Ickes, L., Kurten, A., Kupc, A., Metzger, A., Riccobono, F., Rondo, L., Schobesberger, S., Tsagkogeorgas, G., Wimmer, D., Amorim, A., Bianchi, F., Breitenlechner, M., David, A., Dommen, J., Downard, A., Ehn, M., Flagan, R. C., Haider, S., Hansel, A., Hauser, D., Jud, W., Junninen, H., Kreissl, F., Kvashin, A., Laaksonen, A., Lehtipalo, K., Lima, J., Lovejoy, E. R., Makhmutov, V., Mathot, S., Mikkila, J., Minginette, P., Mogo, S., Nieminen, T., Onnela, A., Pereira, P.,
Petaja, T., Schnitzhofer, R., Seinfeld, J. H., Sipila, M., Stozhkov, Y., Stratmann, F., Tome, A., Vanhanen, J., Viisanen, Y., Vrtala, A., Wagner, P. E., Walther, H., Weingartner, E., Wex, H., Winkler, P. M., Carslaw, K. S., Worsnop, D. R., Baltensperger, U., and Kulmala, M.: Role of sulphuric acid, ammonia and galactic cosmic rays in atmospheric aerosol nucleation, Nature, 476 , 429-433, doi:10.1038/nature10343, 2011.

Krause, S., Clark, H. M., Ferris, J. P., and Strong, R. L.: Chemistry of the environment, Elsevier Science \& Technology Books, 2002.

Kruis, F. E., Fissan, H., and Peled, A.: Synthesis of nanoparticles in the gas phase for electronic, optical and magnetic applications a review, J. Aerosol Sci., 29, 511-535, 1998.

$\mathrm{Ku}$, B. K. and Fernández de la Mora, J.: Relation between electrical mobility, mass, and size for nanodrops 1$6.5 \mathrm{~nm}$ in diameter in air, Aerosol Sci. Tech., 43, 241-249, doi:10.1080/02786820802590510, 2009.

Kulmala, M., Maso, M. D., Mäkelä, J. M., L. Pirjola, Väkevä, M., P. Aalto, Miikkulainen, P., Hämeri, K., and O'Dowd, C. D.: On the formation, growth and composition of nucleation mode particles, Tellus, 53B, 479-490, 2001.

Kulmala, M., Riipinen, I., Sipila, M., Manninen, H. E., Petaja, T., Junninen, H., Maso, M. D., Mordas, G., Mirme, A., Vana, M., Hirsikko, A., Laakso, L., Harrison, R. M., Hanson, I., Leung, C., Lehtinen, K. E., and Kerminen, V.-M.: Toward direct measurement of atmospheric nucleation, Science, 318, 89-92, doi:10.1126/science.1144124, 2007.

Kulmala, M., Petaja, T., Nieminen, T., Sipila, M., Manninen, H. E., Lehtipalo, K., Maso, M. D., Aalto, P. P., Junninen, H., Paasonen, P., Riipinen, I., Lehtinen, K. E., Laaksonen, A., and Kerminen, V.-M.: Measurement of the nucleation of atmospheric aerosol particles, Nat. Protoc., 7, 1651-1667, doi:10.1038/nprot.2012.091, 2012.

Kulmala, M., Kontkanen, J., Junninen, H., Lehtipalo, K., Manninen, H. E., Nieminen, T., Petaja, T., Sipila, M., Schobesberger, S., Rantala, P., Franchin, A., Jokinen, T., Jarvinen, E., Aijala, M., Kangasluoma, J., Hakala, J., Aalto, P. P., Paasonen, P., Mikkila, J., Vanhanen, J., Aalto, J., Hakola, H., Makkonen, U., Ruuskanen, T., Mauldin, R. L., 3rd, Duplissy, J., Vehkamaki, H., Back, J., Kortelainen, A., Riipinen, I., Kurten, T., Johnston, M. V., Smith, J. N., Ehn, M., Mentel, T. F., Lehtinen, K. E., Laaksonen, A., Kerminen, V.-M., and Worsnop, D. R.: Direct observations of atmospheric aerosol nucleation, Science, 339, 943-946, doi:10.1126/science.1227385, 2013.

Kulmala, M., Hõrrak, U., Manninen, H. E., Mirme, S., Noppel, M., Lehtipalo, K., Junninen, H., Vehkamäki, H., Kerminen, V.-M., Noe, S. M., and Tammet, H.: The legacy of Finnish-Estonian air ion and aerosol workshops, Boreal Environ. Res., 21, 181-206, 2016.

Laakso, L., Petäjä, T., Lehtinen, K. E. J., Kulmala, M., Paatero, J., Hõrrak, U., Tammet, H., and Joutsensaari, J.: Ion production rate in a boreal forest based on ion, particle and radiation measurements, Atmos. Chem. Phys., 4, 1933-1943, doi:10.5194/acp-41933-2004, 2004.

Lange, R., Fissan, H., and Schmidt-Ott, A.: Determination of equivalent diameters of agglomerates, J. Aerosol Sci., 29, S417-S418, 1996.

Laskin, A., Laskin, J., and Nizkorodov, S. A.: Mass spectrometric approaches for chemical characterisation of atmospheric 
aerosols: critical review of the most recent advances, Environ. Chem., 9, 163-189, doi:10.1071/en12052, 2012.

Lehtipalo, K., Sipilä, M., Junninen, H., Ehn, M., Berndt, T., Majos, M. K., Worsnop, D. R., Petäjä, T., and Kulmala, M.: Observations of nano-CN in the nocturnal boreal forest, Aerosol Sci. Tech., 45, 499-509, doi:10.1080/02786826.2010.547537, 2011.

Lewis, C., Hopke, P. K., and Stukelt, J. J.: Solubility of radon in selected perfluorocarbon compounds and water, Ind. Eng. Chem. Res., 26, 356-359, 1987.

Lyubovtseva, Y. S., Sogacheva, L., Maso, M. D., Bonn, B., Keronen, P., and Kulmala, M.: Seasonal variations of trace gases, meteorological parameters, and formation of aerosols in boreal forests, Boreal Environ. Res., 10, 493-510, 2005.

Mäkelä, J. M., Riihelä, M., Ukkonen, A., Jokinen, V., and Keskinen, J.: Comparison of mobility equivalent diameter with Kelvin Thomson diameter using ion mobility data, J. Chem. Phys., 105, 1562-1571, doi:10.1063/1.472017, 1996.

Manninen, H. E., Petäjä, T., Asmi, E., Riipinen, I., Niemnen, T., Mikkilä, J., Hõrrak, U., Mirme, A., Mirme, S., Laakso, L., Kerminen, V.-M., and Kulmala, M.: Long-time field measurements of charged and neutral clusters using Neutral cluster and Air Ion Spectrometer (NAIS), Boreal Environ. Res., 14, 591-605, 2009.

Manninen, H. E., Mirme, S., Mirme, A., Petäjä, T., and Kulmala, M.: How to reliably detect molecular clusters and nucleation mode particles with Neutral cluster and Air Ion Spectrometer (NAIS), Atmos. Meas. Tech., 9, 3577-3605, doi:10.5194/amt9-3577-2016, 2016.

Mason, E. A. and McDaniel, E. W.: Transport properties of ions in gases, John Wiley \& Sons, New York, Chichester, Brisbane, Toronto, Singapore, 1988.

Mattsson, R., Paatero, J., and Hatakka, J.: Automatic alpha/beta analyser for air filter samples - absolute determination of radon progeny by pseudo-coincidence techniques, Radiat. Prot. Dosim., 63, 133-139, 1996.

Mazon, S. B., Kontkanen, J., Manninen, H. E., Nieminen, T., Kerminen, V.-M., and Kulmala, M.: Cluster events in a boreal forest: comparing night-time with day-time ion clusters in 2003-2013, Boreal Environ. Res., 21, 242-261, 2016.

Millikan, R. A.: The general law of fall of a small spherical body through a gas, and its bearing upon the nature of molecular reflection from surfaces, Phys. Rev., 22, 1-23, doi:10.1103/PhysRev.22.1, 1923.

Mirme, A., Tamm, E., Mordas, G., Vana, M., Uin, H., Mirme, S., Bernotas, T., Laakso, L., Hirsikko, A., and Kulmala, M.: A widerange multi-channel Air Ion Spectrometer, Boreal Environ. Res., 12, 247-264, 2007.

Mirme, S. and Mirme, A.: The mathematical principles and design of the NAIS - a spectrometer for the measurement of cluster ion and nanometer aerosol size distributions, Atmos. Meas. Tech., 6, 1061-1071, doi:10.5194/amt-6-1061-2013, 2013.

Nazaroff, W. W.: Radon transport from soil to air, Rev. Geophys., 30, 137-160, 1992.

Nieminen, T., Asmi, A., Maso, M. D., Aalto, P. P., Keronen, P., Petäjä, T., Kulmala, M., and Kerminen, V.-M.: Trends in atmospheric new-particle formation: 16 years of observations in a boreal-forest environment, Boreal Environ. Res., 19, 191-214, 2014.

Nieminen, T., Yli-Juuti, T., Manninen, H. E., Petäjä, T., Kerminen, V.-M., and Kulmala, M.: Technical note: New particle forma- tion event forecasts during PEGASOS-Zeppelin Northern mission 2013 in Hyytiälä, Finland, Atmos. Chem. Phys., 15, 1238512396, doi:10.5194/acp-15-12385-2015, 2015.

Nilsson, E., Paatero, J., and Boy, M.: Effects of air masses and synoptic weather on aerosol formation in the continental boundary layer, Tellus, 52B, 462-478, 2001.

Nolan, J. J.: The constitution of gaseous ions, Phys. Rev., 24, 16-30, doi:10.1103/PhysRev.24.16, 1924.

Paatero, J. and Hatakka, J.: Wet deposition efficiency of short-lived radon-222 progeny in central Finland, Boreal Environ. Res., 4, 285-293, 1999.

Paatero, J., Hatakka, J., Mattsson, R., and Lehtinen, I.: A comprehensive station for monitoring atmospheric radioactivity, Radiat. Prot. Dosim., 54, 33-39, 1994.

Paatero, J., Kyrö, E., Hatakka, J., Aaltonen, V., and Viisanen, Y.: Measurement of snow cover based on external radiation, Seventh International Symposium on The Natural Radiation Environment (NRE-VII), Rhodes, Greece, 20-24 May 2005.

Pumpanen, J., Ilvesniemi, H., Perämäki, M., and Hari, P.: Seasonal patterns of soil $\mathrm{CO}_{2}$ efflux and soil air $\mathrm{CO}_{2}$ concentration in a Scots pine forest: comparison of two chamber techniques, Glob. Change Biol., 9, 371-382, 2003.

Read, J.: A Meteorological Journal, Principally Relating to Atmospherical Electricity; Kept at Knightsbridge, from the 9th of May, 1790 , to the 8th of May, Philos. T. R. Soc. Lond., 82, 225-256, 1792.

Reischl, G. P.: Measurement of ambient aerosols by the differential mobility analyzer method: concepts and realization criteria for the size range between 2 and $500 \mathrm{~nm}$, Aerosol Sci. Tech., 14, 524, doi:10.1080/02786829108959467, 1991.

Rienstra-Kiracofe, J. C., Tschumper, G. S., and Schaefer, H. F.: Atomic and Molecular Electron Affinities: Photoelectron Experiments and Theoretical Computations, Chem. Rev., 102, 231-282, 2002.

Robotti, N.: J. J. Thomson at the cavendish laboratory: The history of an electric charge measurement, Ann. Sci., 52, 265-284, doi:10.1080/00033799500200231, 2006.

Rosell-Llompart, J. and Fernández de la Mora, J.: Minimization of the diffusive broadening of ultrafine particles in differential mobility analysers, Synthesis and measurement of ultrafine particles, Delft, 1993.

Sipilä, M., Berndt, T., Petaja, T., Brus, D., Vanhanen, J., Stratmann, F., Patokoski, J., Mauldin III, R. L., Hyvarinen, A. P., Lihavainen, H., and Kulmala, M.: The role of sulfuric acid in atmospheric nucleation, Science, 327, 1243-1246, doi:10.1126/science.1180315, 2010.

SMEAR: Aerosol and meteorological data at SMEAR II Hyytiälä forest station, Atmospheric Sciences/University of Helsinki (UHEL), available at: http://avaa.tdata.fi/web/smart/smear/, last access: 14 November 2016.

Spaans, E. J. A. and Baker, J. M.: The soil freezing characteristic: its measurement and similarity to the soil moisture characteristic, Soil Sci. Soc. Am. J., 60, 13-19, 1996.

Stranden, E., Kolstad, A. K., and Lind, B.: The influence of moisture and temperature on radon exhalation, Radiat. Prot. Dosim., 7, 55-58, 1984.

Tammet, H.: The aspiration method for the determination of atmospheric-ion spectra, Israel Program for Scientific Translations, Jerusalem, 1970. 
Tammet, H.: Size and mobility of nanometer particles, clusters and ions, J. Aerosol Sci., 26, 459-475, 1995.

Tammet, H.: Continuous scanning of the mobility and size distribution of charged clusters and nanometer particles in atmospheric air and the Balanced Scanning Mobility Analyzer BSMA, Atmos. Res., 82, 523-535, doi:10.1016/j.atmosres.2006.02.009, 2006.

Tammet, H.: Symmetric Inclined Grid Mobility Analyzer for the measurement of charged clusters and fine nanoparticles in atmospheric air, Aerosol Sci. Tech., 45, 468-479, doi:10.1080/02786826.2010.546818, 2011.

Tammet, H.: the function-updated millikan model: a tool for nanometer particle size-mobility conversions, Aerosol Sci. Tech., 46, i-iv, doi:10.1080/02786826.2012.700740, 2012.

Tarvainen, V., Hakola, H., Hellén, H., Bäck, J., Hari, P., and Kulmala, M.: Temperature and light dependence of the VOC emissions of Scots pine, Atmos. Chem. Phys., 5, 989-998, doi:10.5194/acp-5-989-2005, 2005.

Tarvainen, V., Hakola, H., Rinne, J., Hellén, H., and Haapanala, S.: Towards a comprehensive emission inventory of terpenoids from boreal ecosystems, Tellus B, 59, 526-534, doi:10.1111/j.16000889.2007.00263.x, 2007.

Tinsley, B. A.: The global atmospheric electric circuit and its effects on cloud microphysics, Rep. Prog. Phys., 71, 066801, doi:10.1088/0034-4885/71/6/066801, 2008.

Vehkamäki, H.: Classical nucleation theory in multicomponent systems, Springer, Berlin, Heidelberg, New York, 2006.

Vojtek, T., Skoupil, T., Fiala, P., and Bartušek, K.: Accuracy of air ion field measurement, Electromagnetics Research Symposium, Cambridge, USA, 26-29 March 2006.

Walter, M.: From the discovery of radioactivity to the first accelerator experiments, in: From Ultra Rays to Astroparticles. A Historical Introduction to Astroparticle Physics, edited by: Falkenburg, B. and Rhode, W., Springer, 17-47, 2012.
Wiedensohler, A., Birmili, W., Nowak, A., Sonntag, A., Weinhold, K., Merkel, M., Wehner, B., Tuch, T., Pfeifer, S., Fiebig, M., Fjäraa, A. M., Asmi, E., Sellegri, K., Depuy, R., Venzac, H., Villani, P., Laj, P., Aalto, P., Ogren, J. A., Swietlicki, E., Williams, P., Roldin, P., Quincey, P., Hüglin, C., Fierz-Schmidhauser, R., Gysel, M., Weingartner, E., Riccobono, F., Santos, S., Grüning, C., Faloon, K., Beddows, D., Harrison, R., Monahan, C., Jennings, S. G., O’Dowd, C. D., Marinoni, A., Horn, H.-G., Keck, L., Jiang, J., Scheckman, J., McMurry, P. H., Deng, Z., Zhao, C. S., Moerman, M., Henzing, B., de Leeuw, G., Löschau, G., and Bastian, S.: Mobility particle size spectrometers: harmonization of technical standards and data structure to facilitate high quality long-term observations of atmospheric particle number size distributions, Atmos. Meas. Tech., 5, 657-685, doi:10.5194/amt5-657-2012, 2012.

Wilkening, M. H. and Clements, W. E.: Radon 222 from the ocean surface, J. Geophys. Res., 80, 3828-3830, doi:10.1029/JC080i027p03828, 1975.

Wilkening, M. H.: Radon in atmospheric studies: a review, Second special symposium, Bhabha atomic reseach center, Bomday, India, 1981.

Wilson, C. T. R.: The effect of rontgen's rays on cloudy condensation, P. R. Soc. Lond., 59, 338-339, 1895

Wilson, C. T. R.: On the condensation nuclei produced in gases by the action of rontgen rays, uranium rays, ultra-violet light, and other agents, Philos. T. R. Soc. Lond., 192, 403-453, 1899.

Wilson, C. T. R.: Investigations on lightning discharges and on the electric field of thunderstorms, Philos. T. R. Soc. Lond., 221, 73115, 1921. 